\title{
San Juan de Ávila y la llegada de los jesuitas a Córdoba, Andalucía
}

\author{
Wenceslao Soto Artuñedo, S.J.*
}

Fecha de recepción: mayo 2021

Fecha de aceptación: septiembre 2021

\section{Sumario:}

San Juan de Ávila tuvo una estrecha relación con la incipiente Compañía de Jesús, especialmente durante su periodo de introducción y expansión en Andalucía. Cuando conoció a la Compañía de Jesús, le envió sus discípulos y ofreció su red de colegios, renunciando a su proyecto personal y posibilitando el ingreso de la Compañía en Andalucía. Eso proceso se advierte en la fundación del colegio de Córdoba, en conjunción con el Ayuntamiento, la casa de Aguilar y la Compañía, en el que san Juan de Ávila renunció a un colegio suyo previo, en favor del de la Compañía, al que dirigió también sus fuentes de financiación.

\section{Palabras clave:}

Compañía de Jesús; Córdoba; San Juan de Ávila; Casa de Aguilar; Fernández de Córdoba.

\section{St. John of Avila and the arrival of the Jesuits in Cordoba, Andalusia}

\begin{abstract}
:
San Juan de Ávila had a close relationship with the incipient Society of Jesus, especially during its period of introduction and expansion in Andalusia. When he met the Society of Jesus, he sent his disciples and offered his network of schools, renouncing his personal project and making it possible for the Society to enter Andalusia. This process can be seen in the founding of the Córdoba school, in conjunction with the City Council, Aguilar's house and the Society, in which Saint Juan de Ávila resigned from a previous school of his, in favor of the Society's, which he directed also his sources of funding.

\section{Keywords:}

Society of Jesus; Córdoba; San Juan de Ávila; House of Aguilar; Fernández de Córdoba.
\end{abstract}

*Archivo Romano de la Compañía de Jesús (ARSI), https://orcid.org/0000-0001-5834-7734, wsoto@jesuitas.es. 


\section{Wenceslao Soto Artuñedo, S.J.}

\section{San Juan de Ávila y la Compañía}

\subsection{Relación de san Ignacio y san Juan}

Cabe la posibilidad de que se hubieran conocido en Alcalá de Henares, cuando Ignacio llegaba y Ávila acababa sus estudios ${ }^{1}$. San Ignacio pudo haber leído en 1538 el Audi Filia, de Ávila², quien debió tener conocimiento de la Compañía en 1542 cuando un primer discípulo suyo entró en la orden, Cristóbal de Mendoza ${ }^{3}$. En cualquier caso, el primer contacto documentado entre ellos no se produjo hasta 1549 con motivo de las críticas que el dominico Melchor Cano vertía sobre la Compañía desde el año anterior en Salamanca.

Este fraile dominico se había mostrado muy desafecto a la nueva orden jesuita en la segunda sesión del concilio de Trento a la que acudió como teólogo del emperador. Allí se produjo una agria discusión con Diego Laínez que asistía en calidad de teólogo pontificio, en la que, después de dos horas de discusión, Laínez ante la contumacia de su interlocutor, "echó á Melchor Cano adonde suelen echar los españoles á quien les fastidia demasiado"4, de lo que inmediatamente se arrepintió y pidió perdón. Vuelto a España propagó sus invectivas contra la Compañía, que fueron contradichas, entre otros, por su correligionario Fr. Juan de la Peña ${ }^{5}$.

San Ignacio y los jesuitas se alarmaron mucho por estos injustos ataques que minaban la credibilidad de una orden nueva en un lugar estratégico como era Salamanca, y fueron la ocasión de que san Ignacio, queriendo sumar alia-

\footnotetext{
${ }^{1}$ Tesis defendida por Francisco de Borja Luque, siguiendo a Miguel Avilés. Ignacio llegó a Alcalá entre marzo y agosto de 1526, con lo que es posible que coincidiera con san Juan de Ávila al final del curso 1525-26. "Profesor mantiene papel crucial de san Juan de Ávila en fundación de jesuitas", acceso 29 octubre 2021. https://www.lavanguardia.com/vida/20191022/471144407746/profesormantiene-papel-crucial-de-san-juan-de-avila-en-fundacion-de-jesuitas.html.

${ }^{2}$ Enrique García Hernán, «Ignacio de Loyola y Juan de Ávila en 1538», en Entre todos, Juan de Ávila, ed. por M. ${ }^{a}$ Encarnación González Rodríguez (Madrid: BAC, 2011), 129-132.

${ }^{3}$ Este es el año de su entrada y no 1545, que dan otros, como consta de su carta a Ignacio, desde Gandía, de 1 de septiembre de 1549: "siento que en siete años que e estado en la Compañía me aprovechado muy poco". Cristóbal Mendoza a Ignacio de Loyola, 01.09.1549, Epistolae Mixtae ex variis europae locis ab anno 1537 ad 1556 scriptae, 5 vol. (Madrid, 1898-1901) [en adelante EppMixtae] II, 276; cf. Francisco de Borja Medina, «El proceso fundacional de la provincia de Andalucía (15451554)», en Los jesuitas en Andalucía. Estudios conmemorativos del 450 aniversario de la fundación de la Provincia, ed. por Wenceslao Soto Artuñedo (Granada: Editorial Universidad de Granada / Facultad de Teología, 2007), 49-162.

${ }^{4}$ Según Astrain, Cano, aunque decía que el Instituto había sido aprobado por el papa, trataba a los fundadores de la Compañía como hipócritas, y atacaba sus personas, pero sin datos concretos ni pruebas y de modo innoble en el modo. Antonio Astrain, Historia de la Compañía de Jesús en la Asistencia de España, 7 vol. (Madrid: Razón y Fe, 1902-1925), I, 563, 328.

${ }^{5}$ Biblioteca Universidad Granada [BUG], Biblioteca Hospital Real [BHR], B-50: Juan de Santibáñez, "Historia de la Provincia de Andalucía de la Compañía de Jesús”, Parte I, libro 1, cap. 9.
} 


\section{SAn Juan de Ávila y la llegada de los Jesuitas a CóRdoba, Andalucía}

dos, escribiera al maestro Ávila el 24 de enero de $1549^{6}$. Reconocía, así, su gran autoridad en todo el territorio y le pedía su intercesión y su consejo en ese tema, además de agradecerle sus favores a la Compañía ${ }^{7}$. Ignacio envió su carta a través de Francisco de Borja, que mandó a un criado suyo con dinero a Alcalá de Henares para que Francisco Villanueva ${ }^{8}$ visitase al maestro Ávila, le informase directamente sobre la Compañía y le llevase esta y otras cartas. Polanco supone que cumplió bien su cometido ${ }^{9}$, si bien no parece que efectuara el viaje hasta 1553, como veremos después. No obstante, la carta llegó a su destinatario, probablemente a través de Cristóbal de Mendoza, en el mes de abril de 1549 y Ávila la respondió el 13 de ese mes, expresando su estima hacia la Compañía, y aconsejando algunas acciones para la buena introducción de la nueva orden y su éxito en España ${ }^{10}$. Posteriormente también se entrevistó con Jerónimo Nadal en 1554, quien le pidió su parecer por escrito sobre los Ejercicios Espirituales ${ }^{11}$.

\subsection{Proyectos paralelos}

Mientras la Compañía daba sus primeros pasos en Andalucía, san Juan de Ávila ya hacía tiempo que actuaba como un apóstol muy reconocido, e incluso había iniciado un movimiento de reforma de la Iglesia con un grupo de discípulos que se diseminaban por Andalucía recorriendo campos y ciudades para predicar y dar catequesis. Pero su iniciativa también cubrió otros campos además de la predicación, por ejemplo:

1) En Córdoba inició unas cátedras de teología y estableció una escuela sacerdotal (1546) en el Alcázar Viejo, para que con su vida austera, interioridad y celo se prepararan los sacerdotes para las misiones en pueblos, y para la dirección espiritual y la formación de la juventud, tanto en la Universidad de Baeza como en los colegios promovidos por él ${ }^{12}$.

\footnotetext{
${ }^{6}$ Sancti Ignacii Loyola Societatis Iesu fundatoris epistolae et instructiones, 12 vol. (Madrid 19031911, reimpresión 1964-1968) [en adelante EppIgn], II, 316-320.

${ }^{7}$ Vita Ignatii Loiolae et rerum societatis Iesu, Historia. Auctore Joanne Alphonsus de Polanco, 6 vol, (Madrid 1894-1898) [en adelante Chron] I, no 465, 433; EppIgn II, 316-317.

${ }^{8}$ Alfredo Verdoy, «El jesuita Padre Villanueva (1509-1557)», Manresa 68 (1996): 405-428; Carlos López Pego, «El inusitado y extraño fenómeno vocacional de los estudiantes de la Universidad de Alcalá hacia la Compañía de Jesús (1545-1634)», Hispania Sacra LXI (2009): 159-190; Juan Díaz Risco, «Francisco de Villanueva, primer jesuita alumno de la Universidad de Alcalá», Anales Complutenses XXVII (2015): 163-191.

${ }^{9}$ Chron I, no 465.

${ }^{10}$ Sala, Obras completas (1970), Carta 190, 93-895.

${ }^{11}$ Sala, Obras completas (1970), 164-165.

${ }^{12}$ Ávila, San Juan de, en Diccionario Histórico de la Compañía de Jesús, 4 vol. [DHCJ], dirigido por Charles O’Neill y Joaquín M. a Domínguez, (Roma / Madrid: Institutum Historicum S. I. / Uni-
} 


\section{Wenceslao Soto Artuñedo, S.J.}

Probablemente esta escuela sacerdotal hubiera acabado por convertirse en una congregación religiosa de clérigos.

2) Por su consejo, había fundado en Baeza el doctor Rodrigo López, una escuela de niños de leer y escribir, estudio de gramática y una cátedra de lección de Sagrada Escritura, a lo que se añadió Artes y Teología poco después de conseguir el rango de universidad por bula de Paulo III en $1542^{13}$.

3) Había creado una red de escuelas para niños, como la de Priego de Córdoba, dotada por la condesa de Feria, cuyo edificio construyó junto a la iglesia de San Nicasio ${ }^{14}$; también en Jerez de la Frontera, Beas de Segura, Úbeda, Cazorla, ... en total, 15 en Andalucía, más la de Alcalá de Henares y Évora.

Con la perspectiva posterior que nos ofrece la Historia, san Juan de Ávila puede ser considerado como el precursor de la Compañía, pues él y san Ignacio pusieron en marcha proyectos paralelos en bastante medida y el de Ávila sirvió de plataforma para el de Ignacio en Andalucía. Semejante idea le transmitió al P. Villanueva en su entrevista en Montilla en 1553, una vez que el jesuita le explicó lo que era la Compañía: "eso es tras lo que yo andaba tanto tiempo" y "no me salía porque Nuestro Señor había encargado esa obra a otro que es vuestro Ignacio, a quien ha tomado por instrumento de lo que yo deseaba hacer y no acababa" ${ }^{15}$. Repitió la misma idea poco después a Jerónimo Nadal1": "Deciame él a mi vn dia: "Yo he sido como vn nino que trataba muy de veras subir vna piedra por vna cuesta boltando, y nunca puede, y viene vn hombre, y facilmente sube la piedra: ansi ha sido el P. Ignatio" ${ }^{17}$. Ávila vio a la Compañía como la ayuda apostólica que la Iglesia necesitaba en aquel tiempo, y que él tanto había deseado y luchado por lograr: “(...) que no halla donde poner los ojos y el corazón para descansar de las calamidades que ve en la Iglesia ahora, sino con mirar a la Compañía, y cierto él la reconoce y abraza

versidad Pontificia de Comillas, 2001; Santibáñez, parte $1^{\mathrm{a}}$, libro $1^{\circ}$, cap. 4, cap. 8; Luis Sala Balust, «La escuela sacerdotal del P. Ávila y la Compañía de Íñigo de Loyola (1546-1556)», en Sala, Obras completas (1970): 108-185.

${ }^{13}$ Ver, por ejemplo, Francisco Juan Martínez Rojas, «La formación cultural del clero giennense en el período pretridentino y la labor renovadora de san Juan de Ávila y la Universidad de Baeza», $X X$ Siglos 14/52 (2003): 65-73.

${ }^{14}$ Luis Sala Balust, Obras completas del Santo Maestro Juan de Ávila (Madrid: BAC, 1952), 130.

${ }^{15}$ Chron I, $\mathrm{n}^{\circ} 465,433$.

${ }^{16}$ Manuel Ruiz Jurado, Jerónimo Nadal. El teólogo de la gracia y la vocación (Madrid: BAC, 2011), 52; Juan Nadal Cañellas, Jerónimo Nadal: vida e influjo (Bilbao: Mensajero, 2007).

${ }^{17}$ Jerónimo Nadal a Ignacio de Loyola, Valladolid, 15.03.1554, Epistolae P. Hieronymi Nadal Societatis Iesus ab anno 1546 ad 1577 (et alia scripta), 5 vol. [en adelante Natalis] (Madrid-Roma, 1898-1962): I, 226. 


\section{SAn Juan de Ávila y la llegada de los Jesuitas a CóRdoba, Andalucía}

como Simeón"18. Por su parte, san Ignacio se había referido a la similitud de proyectos en 1550: “(...) que en tanta uniformidad de voluntades y modo de proceder del Mtro. Avila y nosotros, que no me parece que quede sino que, o nosotros nos juntemos con él, o él con nosotros, para que las cosas del divino servicio mejor se perpetúen" 19 .

La estima de Ignacio hacia el maestro Ávila se pone de relieve en la siguiente anécdota. Llegaron a Roma Diego de Guzmán (discípulo de Ávila hecho jesuita) y Jerónimo Nadal, y quiso san Ignacio, que estaba enfermo, que esos huéspedes cenasen con él, y en la sobrecena san Ignacio requirió a Guzmán información sobre Ávila, a lo que respondió: "Ya ha años que no le veo; porque tantos ha que nos envió al Padre Doctor Loarte -estaba también allí presente- y a mí a Oñate, para que el Padre Francisco de Borja nos recibiese en la Compañía, y nos dixo: Andad, hijos, que quizá seré yo como Jacob, que envió sus hijos por delante, y después fue tras ellos". A esto añadió el P. Nadal: "Muchas veces trató conmigo el Venerable Maestro Ávila esta materia de entrar en la Compañía; pero como humilde, parécele que estando ya tan viejo y tan gravado de enfermedades, no ha de ser provecho sino carga a la Religión". A esto dijo san Ignacio: "Quisiera el santo Maestro Ávila venirse con nosotros, que le traxéramos en hombros como al arca del Testamento, que diferencia se ha de hacer en las personas" ${ }^{20}$. Hay otra variante de esta réplica de Ignacio: "Quisiera el santo Maestro Ávila venirse con nosotros, que lo trajéramos en hombros, como el Arca del Testamento, por ser el archivo de la Sagrada Escritura, que si esta se perdiere, él solo la restituiría a la Iglesia"21.

Puesto que había tratado varias veces con Nadal su entrada en la Compañía, este había autorizado al primer provincial de la provincia Bética, Miguel de Torres, para admitirlo, cuando iba camino de Córdoba para asumir este oficio, según comunicó a San Ignacio en mayo de 1554. Hubiera ingresado si "fuera algo más joven y no tuviera tantos achaques"22, según recogió Polanco, pero pese a la mutua admiración, el expresado deseo de Ávila de ingresar en la Compañía y el anhelo con el que san Ignacio comunicó que lo recibiría, no llegó a producirse tal evento. Los historiadores han aducido varias razo-

\footnotetext{
${ }^{18}$ Lainii Monumenta. Epistolae et Acta Patris Jacobi Lainii secundi praepositi generalis Societatis Iesu, 8 vol. [en adelante Lainii] (Madrid 1912-1917): 3, 173.

${ }^{19}$ Anotaciones de Polanco: «Una letra mostrable a Ávila donde diga...», Polanco a Francisco Villanueva ex Comm. Roma 2 ó 3.09.1550, Sancti Ignacii Loyola Societatis Iesu fundatoris epistolae et instructiones, 12 vol. Madrid 1903-1911, reimpresión 1964-1968 [en adelante EppIgn:] III, 162.

${ }^{20}$ Obras del Venerable Maestro Juan de Ávila, clérigo, apóstol de la Andalucía, tomo noveno (Madrid: Imprenta Real, 1806), 323-324; Vida del venerable padre maestro Juan de Ávila ...: compendiada y extractada ...por Fray Joaquín de Pineda Ramírez de Arellano (Madrid: 1790), 60-61.

${ }^{21}$ Proceso de Beatificación de Juan de Ávila, f. 1016, b; Sala, Obras completas (1970), 209-210.

${ }^{22}$ Chron I, no 465, 433.
} 


\section{Wenceslao Soto Artuñedo, S.J.}

nes: su delicada salud desde 1551, según expresó el mismo Ávila; los impedimentos para que cristianos nuevos formasen parte de la orden ignaciana; el nombramiento de Bartolomé Bustamante como provincial de Andalucía (1556-1561) ${ }^{23}$; incluso su deseo de no causar más problemas a la Compañía por el tema de los conversos ${ }^{24}$.

De hecho, no llegó a ingresar, pero en sus últimos años de retiro en Montilla, vivía en estrecho contacto con los jesuitas del colegio a quienes visitaba frecuentemente, y ofrecía su consejo. No obstante, con el provincial Juan de Cañas se le puso alguna dificultad a estas visitas, según denunció el P. Juan de Vergara al P. General:

El P. Maestro Ávila solía algunas [veces] de antes venirse a este colegio y estarse una semana o dos, (...). Estos días pasados lo quiso hacer, y temiendo que el Provincial fuese estrecho en esto, me dijo que le escribiese sobre ello, y respondióme que él quisiera de todo corazón, pero que le parecía que no podía dar aquella licencia, y así le respondió al Maestro, el cual aunque al presente mismo me dijo sino que le parecía bien lo que hace el P. pero después con otros padres de la Compañía se quejó y que lo había tenido por sequedad, parecióme proponerlo a V: P. para que en ello vea lo que conviene (... $)^{25}$.

A pesar de todo, prevaleció la sintonía.

\subsection{Colaboración}

Dada la simpatía mutua, se produjo una gran colaboración entre la Compañía y san Juan de Ávila, de la que, a modo de ejemplo, indicamos algunos ámbitos:

a) Traspaso de discípulos

Ávila estaba tan complacido por la obra de Ignacio que a todos sus discípulos que veía aptos les aconsejaba que entraran en la Compañía ${ }^{26}$. En la entrevista mantenida con Jerónimo Nadal poco después de su llegada a Córdoba

\footnotetext{
${ }^{23}$ María Amparo López Arandia, «¿Caminos encontrados? Juan de Ávila y la Compañía de Jesús», en El maestro Juan de Ávila (1500-1569). Un exponente del humanismo reformista, editado por M. ${ }^{a}$ Dolores Rincón González y Raúl Manchón Gómez (Salamanca / Jaén: Universidad Pontificia de Salamanca / Universidad de Jaén, 2014), 567-591.

${ }^{24}$ Mariano Delgado, «(...) todos los males y perturbaciones de la Compañía han venido de ellos" Reflexiones acerca del giro anti-converso en la Compañía de Jesús», en Diego Laínez (1512-1565) and his Generalate. Jesuit with Jewish Roots, Close Confidant of Ignatius of Loyola, Preeminent Theologian of the Council of Trent, ed. por Paul Oberholzer (Roma: Bibliotheca Instituti Historici Societatis Iesu, 2015), 192-213.

${ }^{25}$ Archivum Romanum Societatis Iesu [ARSI], Hispania [Hisp], 106, 177: Juan de Vergara, Montilla, 17.07.1567.

${ }^{26}$ Chron I, n' 465,433 .
} 
el 23 de diciembre de 1553, departieron sobre el ingreso de los discípulos más aptos en la Compañía, si bien no le parecía bien a Ávila que el criterio fuese ser o no cristiano viejo, según entendía él que era la práctica seguida por Antonio Araoz y Diego Mirón. Como prueba de que esa no era la actitud habitual en la Compañía, Nadal admitió a Luis de Santander (hijo de cristianos nuevos), por indicación de Ávila ${ }^{27}$.

Acabarán ingresando en la Compañía, al menos, una treintena de sus seguidores $^{28}$, abasteciendo así a la naciente orden de magníficos apóstoles que constituyeron una primera generación de jesuitas españoles, y un buen cimiento para la construcción de la nueva provincia de Andalucía.

En el colegio sacerdotal del Alcázar Viejo había reunido unos 24 sacerdotes ocupados en las cátedras del colegio y en los ministerios de la predicación, catequesis y misiones populares. Entre ellos se contaban futuros miembros de la Compañía, como el rector del colegio, Diego de Barajas, D. Diego de Guzmán, Alonso de Barzana ${ }^{29}$ y los dos hermanos Loarte, Gaspar y Baltasar, residentes en Granada. A éstos hay que añadir el lector de gramática, Francisco de Toledo, cordobés, teólogo y futuro cardenal, y el licenciado Francisco Gómez, natural de Fregenal, obispado de Badajoz. Fue traído por Ávila hacia 1552, para leer un curso de Artes y acabado éste, comenzó a enseñar en la cátedra de Teología. Atendía el internado puesto en marcha por Ávila, dirigido por el licenciado Gonzalo Hernández, situado "en las tendillas que llaman de Calatrava". Pero no duró mucho el convictorio, pues los dos sacerdotes que lo atendían entraron en la Compañía de Jesús en $1559^{30}$.

\section{b) Oferta de traspaso de los colegios}

En 1552 Ávila ofreció al provincial Antonio Araoz traspasar sus colegios a la Compañía, y en la entrevista con Nadal trataron del colegio de Baeza, pero era algo que también dependía del otro patrono, y, finalmente, no se llegó a realizar, permaneciendo allí, por algún tiempo, la escuela de Ávila en un grupo de discípulos ${ }^{31}$. Similar oferta se intentó con las escuelas de Jerez de la Frontera, Beas de Segura y otros lugares ${ }^{32}$, pero, en general no se llegó a

\footnotetext{
${ }^{27}$ Sala, Obras completes (1970): 164-165.

${ }^{28}$ Véase su elenco provisional en Archivum Historicum Societatis Iesu 39 [1970] 158.

${ }^{29}$ Wenceslao Soto Artuñedo, «Alonso de Barzana, S. I. Apóstol de Andalucía y Sudamérica», Archivo Teológico Granadino 79 (2016): 5-130; Wenceslao Soto Artuñedo, «El deseo de las Indias: las cartas indipetas de Alonso de Barzana SJ (1530-1598)», Archivum Historicum Societatis Iesu, 85/170 (2016): 405-444; Wenceslao Soto Artuñedo, Alonso de Barzana, SJ, (1530-1597), el Javier de las Indias Occidentales, (Bilbao: Mensajero, 2018).

${ }^{30}$ Sala, Obras completas, (1970), 170-173.

${ }^{31}$ Sala, Obras completas, (1970), 164-165; Borja Medina, «El processo fundacional».

32 Juan de Santibáñez, parte $1^{\mathrm{a}}$, libro $1^{\mathrm{o}}$, cap. 10; Borja Medina, «El proceso fundacional».
} 


\section{Wenceslao Soto Artuñedo, S.J.}

efectuar el traspaso de colegios a los jesuitas, salvo el de Córdoba, en la forma que veremos.

\section{c) Seminario de la Asunción}

También apuntó la posibilidad de entregar a la Compañía el seminario de la Asunción ${ }^{33}$ que, por su indicación, había fundado en Córdoba el doctor Pedro López de Alba, médico de Carlos V. Era una obra pía para ayudar a jóvenes pobres candidatos al sacerdocio, que fundó dicho doctor residiendo en Córdoba, dado que no tenía herederos. Para ello, el 6 de diciembre de 1569 compró las casas de Alfonso Fernández de Argote y su mujer Juana de Angu$10^{34}$. La intención de entregarlo a la Compañía se llevaría a cabo primero con la superintendencia y después con la dirección:

El 15 de agosto de 1577 se alcanzó de Gregorio XIII una bula para fundar y erigir ese colegio y hacer constituciones y reglas. Antes había alcanzado de Mercurián en 1576 que admitiese al Rector de Córdoba, al de Montilla y al Provincial, que si no pudiese poner un rector de la Compañía, al menos pusiese un secular, igual que al patrón que se nombrase, que podría poner y quitar libremente la Compañía $a^{35}$.

d) Transmitió su generosidad hacia la Compañía a otros discípulos

Contagió su propia estima por la Compañía a sus discípulos y seguidores. Uno de ellos fue el sacerdote Alonso de Molina, por cuyo consejo, siendo novicio de la Compañía, salió de ella, porque, según le dijo, sería más útil fuera, sin las obligaciones de un religioso, pero se convirtió en benefactor de los jesuitas:

Además de las ordinarias limosnas de ropa, de lienzo y lana, regalos para enfermos, dinero que con abundancia enviaba dio por 15 años consecutivos 80 (50) ducados para la fábrica de la Iglesia y ésta acabada hizo donación del principal, en su muerte, dexó por eredero al Collegio del resto de su hacienda no de poca consideración. Persuadió a doña Beatriz de Góngora, que aumentase con su hacienda este colegio. Dejó 7.000 ducados que ella valía. Acabó también con su hermano Francisco de Molina que dejase a la Compañía el remanente de sus bienes que llegaron a tres mil ducados y con estas y otras limosnas que se juntaron se compraron entonces el año de 1583 las tierras de sementera que tiene en el pago que llaman la Guijarrosa, término de la Rambla, con que cum-

\footnotetext{
${ }^{33}$ Juan Aranda Doncel, «Instituciones educativas andaluzas en el Antiguo Régimen: las constituciones del Colegio de la Asunción de Córdoba durante el siglo XVI», Boletín de la Real Academia de Córdoba, de Ciencias, Bellas Artes y Nobles Letras LVIII/112 (1987): 5-22.

${ }^{34}$ Teodomiro Ramírez de Arellano, Paseos por Córdoba, 1873-1875, $1^{\text {a }}$ edición facsímil de 1873, Librería Luque 1973², Valladolid 2003.

${ }^{35}$ BUG, BHR, caja A-049 (8), «Algunos beneficios que ha habido en este colegio».
} 


\section{SAn Juan de Ávila y la llegada de los Jesuitas a CóRdoba, Andalucía}

plió este Colegio la obligación que su fundador le dejó de comprar tierras que rentasen al año diez cahíçes ${ }^{36}$ de trigo para su gasto, como consta de la escritura de concordia que se hiço con los herederos del fundador, que dieron para este efecto mil y seiscientos ducados en cambio de 600 fanegas de trigo que les mandó dar al colegio para que en forma de depósito siempre se conservasen para tiempos de esterilidad y no avían dado sino 105 y así redimieron su obligación cargándose el Colegio de comprar las tierras que concertó.

Por todo ello, al morir en 1595 fue enterrado en la misma sepultura de los jesuitas y el noveno día celebró sus exequias y predicó a ellas el provincial Cristóbal Méndez Lobo ${ }^{37}$.

\subsection{Jesuita post mortem}

Se puede decir que, de alguna manera, Juan de Ávila ingresó post mortem en la Compañía, al menos su cadáver. La marquesa de Priego y su nuera, sor Ana de la Cruz, le propusieron enterrarlo en el convento de Santa Clara, "mas él respondió que no, sino en el Colegio de los padres de la Compañía, a los cuales como había amado en vida, quísoles dejar esta prenda en su muerte"38. Debió haberlo expresado hacía tiempo pues este deseo suyo fue autorizado por el prepósito general Laínez, ya que era preceptivo este permiso para enterrar a no jesuitas en sus templos: “A. P. Maestro Ávila [...] la sepultura se le conceda en donde fuera su voluntad libremente" ${ }^{39}$. Cuando le llegó la hora postrera, el 10 de mayo de 1569, se halló a la cabecera de su lecho el rector de Montilla, P. Juan de Vergara, que informó al P. General, así como de la marquesa de Priego, fallecida poco después, impactada por la muerte del maestro:

De vuelta [de Córdoba] hallé al P. maestro Ávila ya al cabo, y estuvimos de casa a su tránsito, que, aunque no fue con aquella manifestación de quien él era que teníamos imaginada, fue como nuestro Señor le quiso hacer la merced, hasta casi espirar, de cubrirlo de dolores; de manera que él, que tenía consejo para todos, allí le servían mis mendrugos; pero esto de manera, que en la entereza de su espíritu guardaba el ser que siempre, como lo mostraba en algunas respuestas que daba a los que le preguntaban por qué no hablaba más. Pidió que le enterrásemos en el colegio, y aunque le importunaron allí de parte de la marquesa y sus hermanas para Santa Clara, se estuvo en lo dicho; y así

\footnotetext{
${ }^{36}$ Cahíz = medida castellana de áridos que equivale a 12 fanegas de tierra.

${ }^{37}$ BUG, BHR: Martín de Roa, «Historia de la Compañía de Jesús en la Provincia de Andalucía», Libro 1, cap. 9.

${ }^{38}$ Fray Luis de Granada, Vida del Padre Maestro Juan de Ávila y las partes que ha de tener un predicador evangélico (Madrid, 1588, Edibesa 2000), cap. VI.

${ }^{39}$ ARSI, Hisp. 67, 3v, Laínez al Provincial, Roma 9.09.1564.
} 


\section{Wenceslao Soto Artuñedo, S.J.}

le enterramos en la capilla de nuestra iglesia; y lo tenemos por una grande reliquia ${ }^{40}$.

Al sepelio acudió el pueblo acompañando al estado eclesiástico y seglar, en tanta cantidad de gente que sólo una pequeña parte cabía en el interior del templo. Los jesuitas le dieron un trato singular a su sepultura, pues no lo enterraron en el suelo del templo, para que nadie lo pisase, sino que pareció más conveniente la pared de la capilla mayor, que era de los marqueses de Priego, en el lado del Evangelio, junto a un altar colateral. Se abrió allí un hueco formando un arco, donde depositaron la caja que contenía el cuerpo, y debajo de este mausoleo se puso una lápida de mármol blanco, con un epitafio redactado por el P. Jerónimo López ${ }^{41}$.

Tras la expulsión de los jesuitas de 1767, favoreció la vuelta de los jesuitas a Montilla la generosidad del conde de la Cortina que les entregó el antiguo templo y concluyó la nueva iglesia de la Encarnación. Entonces fueron trasladados a ella los restos de S. Juan de Ávila en 1949 al lado del evangelio del crucero, y, cuando se produjo su canonización el 31 de mayo en 1971, fueron depositados en el altar mayor, obra de Félix Granda, introduciendo la antigua urna de plata en una de madera policromada.

\section{Protagonistas del proceso de fundación}

La sintonía entre el maestro Ávila y la Compañía tuvo como escenario principal la diócesis de Córdoba, especialmente las ciudades de Córdoba y Montilla, pues el santo dejó a la Compañía como heredera de su proyecto de colegio de Córdoba, puesto en marcha en 1539 para cuya financiación había entablado conversaciones con el Ayuntamiento años atrás. Él renunció a su propósito y traspasó a la Compañía los recursos prometidos por el Ayuntamiento, que facilitaron el primer colegio jesuita de Andalucía, el de Santa Catalina, que supuso la llegada de los jesuitas al Sur de España. También fue clave su papel en la fundación del colegio de Montilla.

La inauguración del colegio de Córdoba fue fruto de la sinergia de varias entidades. Pero, además de san Juan de Ávila, el Ayuntamiento, y la propia Compañía de Jesús, fueron fundamentales para la fundación las siguientes personalidades, todas del linaje de los Fernández de Córdoba: Don Antonio de Córdoba, Doña Catalina Fernández de Córdoba y Don Juan de Córdoba.

\footnotetext{
${ }^{40}$ ARSI, Hisp. 111, 86, Juan de Vergara al P. Francisco de Borja, Montilla, 24.07.1569.

${ }^{41}$ Antonio Jiménez Fernández, El sepulcro y el cuerpo de San Juan de Ávila (Montilla 1986).
} 


\section{San Juan de Ávila y la llegada de los Jesuitas a CóRdoba, Andalucía}

Los precursores de la llamada casa de Córdoba fueron los linajes castellanos de Témez y Muñoz, que constituyeron un mayorazgo durante la reconquista del valle del Guadalquivir. Con Alfonso Fernández de Córdoba (12841327) se consolidó su patrimonio señorial, cuyo núcleo central fue la villa de Cañete de las Torres. Enrique II hizo que el señorío de Aguilar, entonces en situación de realengo, fuese entregado a Gonzalo Fernández de Córdoba (1343-1384), que adopta el nombre de la villa de Aguilar y constituye el mayorazgo en el que se integran las villas de Montilla, Monturque, Puente de Don Gonzalo y Castillo Anzur. Don Alonso de Aguilar adquirió la villa y castillo de Carcabuey y el lugar de Santa Cruz, además de importantes extensiones de tierras e inmuebles en Córdoba.

El linaje de los Fernández de Córdoba se ramificó en cuatro líneas principales: la Casa de Aguilar (marqueses de Priego desde 1501), la de Cabra (también duques de Sessa y Baena, después), la de los Alcaides de los Donceles o marqueses de Comares, y la del condado de Alcaudete ${ }^{42}$.

Es curioso que este mismo linaje es el nexo en Córdoba entre la antigua Compañía, antes de la expulsión y supresión, y la nueva Compañía, después de su restauración, pues el fundador del antiguo colegio fue un Fernández de Córdoba, y cuando la Compañía vuelve a Córdoba, se instala en la iglesia de San Hipólito, cuyo patronato ostentó una de las ramas de este linaje. Este nexo se simboliza en la custodia de los sepulcros de algunos de sus miembros, tanto en la iglesia de San Hipólito, en Córdoba, como en la de la Encarnación, de Montilla.

Por lo que respecta a la Real Colegiata de San Hipólito ${ }^{43}$, una rama de los Fernández de Córdoba consiguió el patronato de su capilla mayor, por la compra del derecho de enterramiento efectuada por Gonzalo Fernández de Córdoba y Biedma, I Señor de Aguilar y III Señor de Cañete, el 27 de agosto de 1375 , por 3.000 maravedís $^{44}$. El primero en recibir sepultura fue su tercer hijo, fundador de la Casa de Cabra y I Señor de Baena, D. Diego Fernández de Córdoba y Carrillo, que murió en noviembre de 1435. Sus restos yacen en la cripta, cuyo acceso (probablemente por una escalera embutida en el ancho

${ }^{42}$ F. Fernández de Córdoba, Historia y descripción de la Casa de Córdoba (Córdoba: Real Academia de Córdoba, 1954); E. Soria Mesa, «Los Fernández de Córdoba, un linaje de la nobleza española», en I Jornadas Cátedra Gran Capitán (Montilla: Ayuntamiento de Montilla, Cátedra Gran Capitán, 2003), 83-98; M. C. Quintanilla Raso, Nobleza y señoríos en el Reino de Córdoba: la Casa de Aguilar (siglos XIV y XV) (Córdoba: Monte de Piedad y Caja de Ahorros, 1979); Elena Bellido Vela, El desaparecido convento franciscano de San Lorenzo de Montilla. Definición geométrica y representación gráfica, (Tesis Doctoral Universidad de Córdoba 2019), http://geneall.net/H/per_page. php?id=62049

${ }^{43}$ E. Luque Ruiz, «La Real Colegiata de San Hipólito: relicario de historia y de fe», Boletín de la Real Academia de Córdoba 106 (1984): 191-207.

${ }^{44}$ El ducado equivalía a 11 reales castellanos y 1 maravedí o bien 375 maravedíes. 


\section{Wenceslao Soto Artuñedo, S.J.}

muro del presbiterio en el lado de la sepultura de Alfonso XI) se tapió en una reforma hacia 1960, pero su sepulcro vacío y el de su mujer, de estilo renacentista, aunque del siglo XVIII, se pueden contemplar en el brazo de la epístola del crucero. Sobre ellos se sitúan dos escudos heráldicos, que corresponden a D. Diego Fernández de Córdoba (el blasón de la izquierda, con las tres bandas y los castillos) y a D. ${ }^{\text {a }}$ Sancha García de Rojas, su primera esposa (el del lado derecho con las cinco cornejas y las cinco estrellas).

D. Gonzalo también sería enterrado en San Hipólito en 1385, así como D. Alonso, II Señor de Aguilar, fallecido en 1424; D. Pedro, V Señor de Aguilar (1423-1456) padre del Gran Capitán, y su hijo D. Alonso de Aguilar, VI Señor de Aguilar (1447-1501), abuelo de $\mathrm{D}^{\mathrm{a}}$. Catalina, fundadora del colegio de Montilla. En la iglesia jesuita de Montilla se conservan los restos de $\mathrm{D}^{\mathrm{a}}$. Catalina Fernández de Córdoba y otros miembros de su familia.

\subsection{El padre don Antonio de Córdoba}

Tanto para la fundación del colegio de Córdoba como para la llegada de los jesuitas a Andalucía, el detonante fue el cordobés D. Antonio de Córdoba (Suárez de Figueroa y Fernández de Córdoba), al que por ser noble, siendo jesuita, se le mantuvo el tratamiento de don: el "padre don Antonio".

Nació en Córdoba en 1527, hijo de los condes de Feria y marqueses de Priego, y, tan sólo con 12 años, recibió un canonicato resignado en él por D. Pedro de Castilla, para lo que hubo de dispensársele la edad por bula ${ }^{45}$. Tomó posesión de esa canonjía el 16 de noviembre de $1539^{46}$, año en que recibió también la dignidad de maestrescuela del mismo cabildo, por bula expedida por Paulo III el 2 de enero de 1539, dispensando también de la edad para que pudiera obtener dicha dignidad que había resignado en él D. Juan Ruiz de Córdoba. Tomó posesión de la dignidad el 24 de abril de $1540^{47}$, y ese mismo

${ }^{45}$ Archivo Duques Medinaceli [ADM], Priego, 12, 3: «Bula de Paulo III por la que manda al Cabildo cordobés diese la posesión a Don Antonio de Córdoba del canonicato resignado en él por Don Pedro de Castilla, 18.06.1539; Priego 12.4. Bula de Paulo III dispensando la edad al Sr. Don Antonio de Córdoba para obtener un canonicato en la Iglesia de Córdoba por resigna que había hecho en el Dn. Pedro de Castilla».

${ }^{46}$ ADM, Priego, 12,5: «Posesión que a Don Antonio de Córdova se dio de la canonjía (que resigno $\mathrm{D}^{\mathrm{n}} \mathrm{P}^{\mathrm{o}}$. De Castilla en manos del Papa Paulo $3^{\mathrm{o}}$ y de que le despachó Bullas para su provisión) de la Iglesia Catedral de Córdoba. Esta firmada de tres canónigos y de Sancho Ruiz de Córdova notario apostólico».

${ }^{47}$ ADM, Priego, 12,1: «Bula de Paulo III, 02.01 .1539 y despacho de la Dataría, 28.02.1540; Priego, 12,2: Bula de Paulo III por la que manda al cabildo de Córdoba diese la posesión de la dignidad de Maestrescuela a Don Antonio de Córdoba, 02.01.1539; Priego 12,7: Posesión de la Dignidad de Maestrescuela de la iglesia de Córdoba que se le dio al Sr. Don Antonio de Córdoba. Está firmada de tres canónigos y Sancho Ruiz de Córdova, notario apostólico». 


\section{SAn Juan de Ávila y la llegada de los Jesuitas a CóRdoba, Andalucía}

año recibía además un beneficio simple en la parroquia de San Lorenzo ${ }^{48}$. Con todo esto estaba ya bien dotado para una vida holgada, pero recibiría otras posibilidades, pues, su madre, al constituir en 1562 el mayorazgo de Villafranca en favor de su hijo Alonso, determinó que, si éste moría sin descendencia, pasaría a Antonio, previa dispensa, si entonces ya era profeso de la Compañía ${ }^{49}$, para que pudiera retener el mayorazgo ${ }^{50}$.

Estando en el círculo de Juan de Ávila, su madre lo mandó a Salamanca a completar sus estudios. Fue nombrado rector del Colegio mayor de San Bartolomé de la Universidad de Salamanca el 10 de noviembre de $1549^{51}$ y allí fue testigo de las críticas de Melchor Cano a la Compañía, que pudo disipar en conversación con el jesuita doctor Miguel Torres, a través del cual se acercó a la nueva orden religiosa ${ }^{52}$. En verano de 1550 estuvo en la ciudad de Córdoba, reponiéndose de una enfermedad y asistió al cabildo eclesiástico, como canónigo y maestrescuela que era, de donde volvió a Salamanca.

D. Antonio rumiaba la idea de hacerse jesuita, pero su familia había puesto muchas esperanzas en él, incluso su madre y sus hermanos, especialmente D. Gomez, embajador extraordinario del príncipe Felipe en Roma, promovían hacerlo cardenal. Impresionado por el ingreso en la orden ignaciana de su pariente, el duque de Gandía Francisco de Borja, acudió por carta a san Ignacio para que le aconsejase, el 31 de marzo de $1552^{53}$. A Salamanca le escribieron sobre el mismo tema el maestro Ávila y S. Francisco de Borja, y éste último lo visitó, incluso, para ayudarle en su discernimiento. No quiso demorar más la decisión y sin esperar la respuesta de san Ignacio, marchó a Oñate (Guipúzcoa) a pedir a Borja su admisión en la Compañía, que se produjo el 22 de mayo de 1552, con 24 años, después de realizar el mes de ejercicios bajo su orientación. Una vez admitido escribió a su madre, a quien inicialmente perturbó esa decisión; y también a S. Juan de Ávila, con cuyo apoyo sabía que podía contar ${ }^{54}$. Borja se congratuló por la decisión ${ }^{55}$ e Ignacio de Loyola

\footnotetext{
${ }^{48}$ ADM, Priego, 12, 7: «Roma, y junio 18 de 1540. Bulla del Papa Paulo $3^{\circ}$ concediendo al Sr. Dn Antonio de Córdoba un Beneficio simple en la Parroquial de Sn. Lorenzo de la Ciudad de Córdoba. Y en ella se inserta otra bulla para que al dicho se le diese posesión de este beneficio. Es traslado autorizado».

${ }^{49}$ Antonio ya era jesuita y para ser profeso tenía que disponer de los bienes que poseyera en ese momento, y renunciar a los que le pudieran venir después.

${ }^{50}$ Juan Aranda Doncel y Luis Segado Gómez, Villafranca de Córdoba. Un señorío andaluz durante la Edad Moderna (1549-1808) (Córdoba: Andalucía Gráfica, 1992): 166.

${ }^{51}$ Sala "Obras completas" (1970), 128; Santibáñez, "Historia...", parte $1^{\text {a }}$, libro $1^{\circ}$, cap. 11.

${ }^{52}$ Bartolomé Hernández a Ignacio de Loyola, 31.08.1550, EppMixtae, II, 440.

${ }^{53}$ Antonio de Córdoba a Ignacio de Loyola, Salamanca, 31.03.1552, EppMixtae, II, 697-702.

${ }^{54}$ Santibáñez, "Historia...", parte $1^{\text {a }}$, libro $1^{\circ}$, cap. 12.

${ }^{55}$ Francisco de Borja a la marquesa de Priego, Oñate 07.08.1552, Sanctus Franciscus Borgia, quartus Gandiae dux et Societatis Iesu praepositus generalis tertius, 5 vol (Madrid, 1894-1911), [en adelante Borgia], III, 120-121.
} 


\section{Wenceslao Soto Artuñedo, S.J.}

se refiera a ella en septiembre de 1552 , aludiendo ya al proyecto de colegio de Córdoba:

Il quarto è don Antonio de Cordoua, figlolo de la contesa de Feria et marquesa de Pliego, che è vna casata molto richa nella Andalusia, di ottanta milia ducati di intrata in circa et de la prima nobilità di Spagna; et lui è vn giouene di 24 o 25 anni, e reputato tanto uirtuoso et discreto, che li teneuano procurato un capello li soi, che sonno molto grandi apreso il principe, il che sapendo lui, ha vsato più freta in abandonar il mondo; et de Salamanca, doue lui è estato rettore, seguitò il Padre Francisco; et sua madre la marquesa, quantunque le fossi charisimo il figlolo, fu molto consolata de la sua elettione, et uole in ogni modo far vn collegio in Cordoua ${ }^{56}$.

Fue ordenado sacerdote en Burgos en 1553, conde celebró su primera misa en la que predicó Borja y pronunció los últimos votos el 28 de mayo de 1564 en Alcalá de Henares (Madrid).

Concibió la idea de fundar un colegio de la Compañía y escuelas en la parte del reino de Córdoba más a propósito, entregando para ello sus beneficios eclesiásticos y otras rentas por llegar, si bien quien finalmente lo fundó en 1553 fue su pariente el deán D. Juan Fernández de Córdoba, siendo don Antonio su primer rector.

En 1554, fue nombrado colateral del provincial de Castilla, Antonio de Araoz, y superintendente del colegio de Salamanca, así como colateral (junio 1555) de Borja para el cuidado de su salud. Entre 1558 y 1559, fue viceprovincial de Andalucía; después residió casi siempre en Alcalá de Henares. Borja le encargó la salida de Araoz de la corte para ir a Roma a ejercer el cargo de asistente de España que le había asignado la Congregación General II; pero vio el asunto tan dificultoso que le aconsejó ceder.

Débil de salud, con enfermedades de corazón e hígado, murió cuando iba a empezar su oficio de visitador de la provincia de Castilla, el 24 enero de 1569, en Oropesa (Toledo), cuando había accedido a pasar un tiempo en el lugar de veraneo de su tía paterna, condesa consorte de Oropesa, precediendo su muerte en unos meses a las de san Juan de Ávila y su madre. Recibió enterramiento en el panteón de los condes de Oropesa, en el convento de San Francisco ${ }^{57}$, y fue trasladado a Montilla por influjo de su hermano, el dominico Lorenzo Suárez de Figueroa, obispo de Sigüenza y gobernador del Estado de Montilla tras la muerte de su madre Doña Catalina ${ }^{58}$. Recibieron el cadáver en Montilla el P. Francisco Vázquez y todos los jesuitas y lo enterraron en el convento

\footnotetext{
${ }^{56}$ Ignacio de Loyola a Gaspar de Doctis Roma, 10.09.1552, EppIgn IV, 428.

${ }^{57}$ El edificio hoy está convertido en fábrica de harina, si bien los restos de los condes acabaron en la iglesia parroquial.

${ }^{58}$ Ruiz Jurado, Manuel, «Antonio de Córdoba», DHSJ, I, 954.
} 


\section{SAn Juan de Ávila y la llegada de los Jesuitas a CóRdoba, Andalucía}

franciscano de San Lorenzo, pues los jesuitas no consiguieron que el cuerpo descansara en su colegio ${ }^{59}$, si bien suponemos que se trasladó al antiguo colegio jesuita junto con los demás restos de la casa de Aguilar según veremos en el siguiente epígrafe.

Fue uno de los jesuitas de más autoridad y confianza de los tres primeros generales en España.

\subsection{Doña Catalina Fernández de Córdoba, II Marquesa de Priego}

Pedro Fernández de Córdoba ${ }^{60}$ (1470-1517) era hijo de D. Alonso de Aguilar y casó con Elvira Enríquez (1477-1517), hija de Enrique Enríquez, tío de Fernando el Católico, bisabuelo materno de S. Francisco de Borja. Era X Señor de la Casa de Córdoba y VII Señor de Aguilar de la Frontera, Priego, Montilla y otras villas, y fue nombrado I marqués de Priego, por los Reyes Católicos el 9 de diciembre de 1501. Logró escapar de la muerte en lucha contra los musulmanes en Sierra Bermeja (Málaga), en la misma batalla en que murió su padre D. Alonso de Aguilar. Respondiendo a la llamada de rey acudía a la corte cuando falleció en Olías (Toledo) el 24 de enero de 1517 y su cuerpo fue enterrado en la parroquia de Santiago, de Montilla, según había dispuesto en su testamento, en el mismo lugar en que fue sepultada su esposa Elvira Enríquez. D. Pedro era un humanista con una buena biblioteca ${ }^{61}$.

De este matrimonio sobrevivieron cuatro mujeres, entre ellas $\mathrm{D}^{\mathrm{a}}$. Catalina Fernández de Córdoba (1495-1569), que heredó el marquesado ${ }^{62}$ y casó en 1518 con D. Lorenzo Suárez de Figueroa (1495-1528), III conde de Feria a quien en 1520 Carlos I concedió el grado de grande de España de nueva creación. El primogénito de este matrimonio fue Pedro Fernández de Córdoba, IV conde de Feria, que casó con Ana Ponce de León, hija de los duques de Arcos, pero murió en Priego el 28 de agosto de 1552 sin haber heredado el estado de Priego, y sus restos fueron trasladados a la sepultura familiar de la parroquia de Santiago, en Montilla. Su viuda se hizo clarisa con el nombre de Sor Ana

\footnotetext{
${ }^{59}$ Roa, «Historia...», libro 1, cap. 8.

${ }^{60}$ Bellido Vela, «El desaparecido convento».

${ }^{61}$ María de la Concepción Quintanilla Raso, «La biblioteca del marqués de Priego (1518)», En la España Medieval 1 (1980): 347-383; Raúl Molina Recio «Nobleza y poder señorial. Los señoríos andaluces de los Fernández de Córdoba en la Edad Moderna. Territorio, población y economía», en Los señoríos en la Andalucía Moderna. El Marquesado de los Vélez, coord. por Francisco Andújar Castillo y Julián Pablo Díaz López (Almería: Instituto de Estudios Almerienses, 2007), 795-815.

${ }^{62}$ Cf. Raúl Molina Recio, «Formación y evolución del marquesado de Priego en la Edad Moderna. Puente Genil y la casa de Córdoba», en Puente Genil. Pasado y presente. I Congreso de Historia, Puente Genil, coord. por E. Soria Mesa, (Córdoba: Universidad de Córdoba / Ayuntamiento de Puente Genil, 2002), 375-389.
} 


\section{Wenceslao Soto Artuñedo, S.J.}

de la Cruz. Le heredó su hermano Gómez Suárez de Figueroa y Córdoba, como V conde de Feria, que se convirtió en el I duque de Feria el 28 de septiembre de 1567. El tercer hijo de Doña Catalina fue D. Alonso Fernández de Córdoba, que casó con su sobrina Catalina, III Marquesa de Priego y heredera de la Casa de Córdoba. El cuarto hijo fue el jesuita Antonio Fernández de Córdoba, y el quinto Lorenzo Suárez de Figueroa, prior del convento dominico de San Pablo en Córdoba que fue nombrado obispo de Sigüenza (09.05.1579), donde murió el 20 de enero de 1605. Sólo tuvo una hija, María de Toledo y Figueroa, que casó con el II duque de Arcos Luis Cristóbal Ponce de León, y fundó el colegio jesuita de Marchena ${ }^{63}$.

$\mathrm{D}^{\mathrm{a}}$. Catalina fue mecenas espiritual de reformadores como S. Juan de Ávila a quien cedió una casa colindante con su palacio, donde se retiró en la etapa final de su vida (1554-1569), y se convirtió así en consejero y orientador espiritual permanente de la marquesa y de su casa. Cuando en 1546 se pensaba instalar un colegio jesuita en Sevilla, Francisco de Borja pidió ayuda a la condesa de Niebla (su tía doña Ana de Aragón), y también a Da . Catalina, pariente suya y II marquesa de Priego, que prometió ayudar con una renta eclesiástica que tenía en el arzobispado de Sevilla ${ }^{64}$. Según testimonios tempranos del P. Antonio Araoz y de san Pedro Fabro, ya en 1547, cuando aún no había casa de la Compañía en Andalucía, la marquesa de Priego estaba dispuesta a mantener algunos estudiantes del futuro colegio de Sevilla, cuyo número acrecentaría si se instituía un colegio en Córdoba. Pero entonces no eran posibles esas fundaciones por los pocos efectivos personales de la Compañía ${ }^{65}$. Razones tenía el P. General Mercurián cuando reconoce al provincial Bernal en 1574 "y porque de una parte somos tan obligados a aquella ilustrísima casa [de Priego]"66.

Resuelto el problema de la sucesión, el 25 de febrero de 1563 la II marquesa de Priego renunció al gobierno de los estados y mayorazgos de la Casa de Aguilar en su nieta Catalina Fernández de Córdoba y Figueroa. Da . Catalina murió el 14 de julio de 1569, unos dos meses después que S. Juan de Ávila:

Luego el mesmo día [de la muerte de maestro Ávila] le dio a la señora marquesa, de achaque de la pena y del trabajo de estar allí, una tan grave enfermedad, que a los seis o siete días la olearon; y aunque con ayuda de oraciones y medios de acá nuestros le dilató la partida por entonces, de ahí a poco más de dos meses, de la misma enfermedad murió hace hoy diez días o 11. Murió con muchas muestras de su salvación y ayudándola muchos religiosos ${ }^{67}$.

\footnotetext{
${ }^{63}$ Santibáñez, «Historia...», parte $1^{\text {a }}$, libro $1^{\circ}$, cap. 11.

${ }^{64}$ Santibáñez, «Historia...», parte $1^{\text {a }}$, libro $1^{\circ}$, cap. 4 , cap. 8 .

${ }^{65}$ Chron I, $\mathrm{n}^{\circ} 208$.

${ }^{66}$ ARSI, Baet., 1a, 14v: Mercurián a Bernal, 03.05.1574.

${ }^{67}$ ARSI, Hisp. 111, 86, Juan de Vergara al P. Francisco de Borja, Montilla, 24.07.1569.
} 


\section{San Juan de Ávila y la llegada de los Jesuitas a CóRdoba, Andalucía}

Aunque había pensado en tres lugares para su enterramiento (el convento franciscano de San Lorenzo ${ }^{68}$, el de clarisas y la parroquia de Santiago), por disposición testamentaria recibió sepultura en el convento franciscano de San Lorenzo, a las afueras de Montilla. Lo había construido a su costa, y a él había trasladado desde la parroquia de Santiago, en 1566: los restos de sus padres, D. Pedro Fernández de Córdoba, I marqués de Priego, y su esposa; los de su hijo D. Pedro; los de un niño (Lorenzo Suárez de Figueroa, hijo del IV Conde de Feria, muerto en Priego antes de 1552) y una niña (probablemente, Jerónima Ponce de León, hija del I duque de Arcos, Rodrigo Ponce de León y su segunda esposa Juana Girón) que, casualmente, murió en Montilla. Fueron colocados en la capilla mayor, y predicó en las exequias Fray Lorenzo de Figueroa, hijo de la marquesa.

El P. General Francisco de Borja, al recibir la noticia recuerda al Provincial que se le hagan los sufragios debidos como fundadora del colegio de Montilla ${ }^{69}$.

Cuando los jesuitas fueron expulsados de los reinos hispanos en 1767, los franciscanos, dado el estado ruinoso de su convento de San Lorenzo, pidieron el colegio e iglesia de los jesuitas de Montilla. Se les concedió en 1794, y se consumó el cambio de residencia de los franciscanos dos años después, con su archivo y buena parte de su patrimonio artístico, permaneciendo allí hasta $1835^{70}$. Pero los restos de la marquesa de Priego y de los demás miembros de la casa de Aguilar no fueron trasladados hasta el 11 de mayo de 1815, con licencia del obispo de Córdoba, D. Pedro Antonio de Trevilla, a instancia de D. Luis Joaquín Fernández de Córdoba, XIII Marqués de Priego, XIII Duque de Feria y XIV Duque de Medinaceli. El marqués presidió el concurrido cortejo de traslado, en el que los franciscanos portaban una caja forrada de terciopelo negro con las armas del Estado de Priego, que fue colocada en un túmulo preparado al efecto. Al día siguiente predicó el franciscano fray Francisco de Soto. Después de esto, la caja fue colocada en una urna de piedra, de forma piramidal, al lado de la epístola del altar mayor.

Cuando el templo fue de nuevo entregado a los jesuitas en $1944 \mathrm{y}$, concluida la nueva iglesia de la Encarnación, se ubicaron en ella los restos de la marquesa y sus parientes el 10 de septiembre de 1970 en el lugar donde habían permanecido los de San Juan de Ávila, bajo una Piedad y una Virgen de la Paz, ambas de Granda, donde se colocó la lápida conmemorativa y el escudo de la Casa de Aguilar que había estado sobre el túmulo de la antigua iglesia jesuita. Se pensó en invitar a sus herederos (Duques del Infantado, de Medinaceli, de

\footnotetext{
${ }^{68}$ Bellido Vela, «El desaparecido convento».

${ }^{69}$ ARSI, Hisp. 68, 31, El General al Provincial, 18.09.1569.

${ }^{70}$ Bellido Vela, «El desaparecido convento», 401.
} 


\section{Wenceslao Soto Artuñedo, S.J.}

Feria, etc.) pero al final se abrió el sepulcro deprisa y se trasladaron los restos casi en secreto. En la caja de cinc que contenía los huesos de la marquesa se halló un tubo metálico y de cristal, lacrado, con una explicación sobre los restos trasladados por los franciscanos desde San Lorenzo a la iglesia jesuita ${ }^{71}$.

El único retrato conocido de $\mathrm{D}^{\mathrm{a}}$. Catalina y su marido Lorenzo Suárez de Figueroa está en un cuadro de la presentación de Jesús en el templo, actualmente en el museo diocesano de Córdoba, en el que aparecen ambos como donantes, en actitud orante y a tamaño considerablemente menor que los personajes principales del lienzo. Esta pintura formaba parte del retablo de la parroquia de Cañete de las Torres, donde la II Marquesa desplegó su mecenazgo ${ }^{72}$.

\subsection{El deán D. Juan Fernández de Córdoba}

La Casa de Cabra surgió con Diego Fernández de Córdoba y Carrillo (1355-1435), nombrado I Señor de Baena el 4 de mayo de 1386. Casó en primeras nupcias con Sancha García de Rojas Díaz-Palomeque, y después con Inés de Ayala, siendo enterrado en la iglesia de San Hipólito, con su primera esposa. Su nieto, Diego Fernández de Córdoba Montemayor (+ 1481), III Señor de Baena, fue el I Señor de Cabra (30.3.1439) y I Conde Cabra (2.9.1455).

En esta familia vino al mundo D. Juan Fernández de Córdoba en Baena a finales del s. XV. Era el cuarto hijo de Diego Fernández de Córdoba, V Señor de la casa de Baena y III Conde de Cabra, y de su segunda esposa, Francisca de Zúñiga y de la Cerda ${ }^{73}$. D. Diego tuvo 20 hijos, siendo el primogénito, Diego, único fruto del primer matrimonio con Beatriz Enríquez de Velasco, pero murió a los 17 años. El segundo vástago, y primero del segundo matrimonio, homónimo del anterior, falleció también siendo niño, por lo que quedó como heredero del condado de Cabra y casa de Baena Luis Fernández de Córdoba, que casó con Elvira, la única hija del Gran Capitán, II Duquesa de Sessa.

Quedaba D. Juan como segundón de la familia, y, como tal, estaba llamado a seguir la senda de su tío Francisco, por entonces prebendado de la catedral, que llegó a ser obispo de Oviedo, Zamora y Palencia. Otro hermano fue Pedro de Córdoba, Comendador de Montiel y Trece de Santiago, Mayordomo de Fe-

\footnotetext{
${ }^{71}$ B. M. R. L. Memoria de los Huesos que contiene esta urna, 1815 (manuscrito). Se trata de un cuadernillo manuscrito en ocho páginas, el cual se encontraba inserto en el panteón de los marqueses de Priego que se ubicó en 1815 en la iglesia de San Francisco de Asís, donde permaneció hasta que, en 1949, fue trasladado a la iglesia de los jesuitas; Bellido Vela, «El desaparecido convento», 430-432.

72 Pedro Romana, Presentación de Jesús en el templo, segunda década del siglo XVI. Córdoba, Museo Diocesano. M. J., Muñoz López, «Presentación de Jesús en el templo», en Gratia Plena [Cat. Exp.], ed. por Juan José Asenjo Peregrina et al., (Córdoba: Cajasur, 2004), 208-210; Bellido, «El desaparecido convento», 251-252.

${ }^{73}$ Documento de donación del colegio de Córdoba, 1554, ARSI, FG 1404/4, 3.
} 


\section{San Juan de Ávila y la llegada de los jesuitas a CóRdoba, Andalucía}

lipe II y Presidente del Consejo de las Órdenes, de quien proceden, por línea materna, los condes de Luque ${ }^{74}$. Nuestro D. Juan tuvo una carrera meteórica:

El 1 de febrero de 1517 su padre lograba la bula de confirmación pontificia de la magna capellanía o abadía que había fundado en Rute, siendo él nombrado primer abad de la misma. Durante estos años cursó sus estudios en Derecho en Salamanca, doctorándose. El 26 noviembre de 1523, de regreso en Córdoba, tomó posesión del obispado en nombre de Fray Juan de Toledo, partiendo después hacia Italia. A su vuelta desde Roma en 1524, su barco naufragó cerca de Ibiza, siendo él uno de los escasos supervivientes. Tras la muerte de su padre al año siguiente, recibió el señorío de las villas de Rute y de Zambra por partición testamentaria. En 1530 sucedió a su tío en el canonicato doctoral de Córdoba y, entre febrero y abril de ese mismo año, tomó parte en la Congregación de las Iglesias en Madrid como representante del cabildo catedralicio de la ciudad. Poco más tarde fue nombrado maestrescuela y, el 12 de agosto de 1531, presentó las bulas para suceder en el deanato que acababa de quedar vacante. El 15 de noviembre de 1538 renunció la abadía de Rute en su sobrino, don Diego de Córdoba y Aragón, en quien pensaba renunciar igualmente el deanato y su canonjía. No obstante, hubo de retomarla por la repentina muerte del muchacho. En años sucesivos, iría consiguiendo otras prebendas para sí (caso del beneficio de Cabra o del de Iznájar), pero también para parientes, amigos y criados suyos. Finalmente, le sucedería en el cabildo catedralicio otro de sus sobrinos, don Francisco Pacheco de Córdoba, más adelante obispo de Málaga y luego de Córdoba ${ }^{75}$.

Dio un gran impulso a su señorío, por lo que es considerado padre del Rute moderno, que después pasó a su sobrino, el III Duque de Sessa.

Nunca logró, sin embargo, ser nombrado obispo. Cuando murió el prelado de Córdoba Pedro Fernández Manrique en 1540, viajó a la corte con una fuerte suma de dinero, para conseguir la mitra, pero, según parece, lo perdió todo en una noche de juego y fue elegido Leopoldo de Austria, del que se constituyó en antagonista ${ }^{76}$.

\footnotetext{
${ }^{74}$ Cf. F. Fernández de Béthencourt, Historia genealógica y heráldica de la monarquía española, Casa Real y grandes de España, VII (Sevilla, 2003), 75-76.

${ }^{75}$ Díaz Rodríguez, «Córdoba, Juan de», en Diccionario Biográfico Español, ed. por Real Academia de la Historia, XIV (Madrid, 2010), 93-103.

${ }^{76}$ Ver Casos Notables de la Ciudad de Córdoba (1618), Anónimo, n ${ }^{\circ} 54$. Es el mismo documento que se cita también como "Casos Raros de Córdoba", "Diálogos entre Colodro, Excusado y Osario", o "Casos Especialísimos de Córdoba". El manuscrito es anónimo, atribuido al jesuita Sebastián de Escabias (Sala, Obras completas (1950): 266-296). Se estructura en unos noventa relatos cortos de leyendas y hechos históricos de Córdoba, en los que dos cordobeses, llamados Colodro y Excusado (a imitación de dos puertas de la ciudad) comparten, lejos de su tierra, sus conocimientos sobre temas de la nobleza, personajes célebres, misterios y habladurías. Se conservaban varias copias. La del Archivo Municipal de Córdoba fue publicada en folletos por el diario $L a \mathrm{Voz}$ en los años veinte del siglo XX. La de la Real Academia de la Historia fue publicada por Ángel González Palencia en
} 


\section{Wenceslao Soto Artuñedo, S.J.}

Desempeñó para la Corona servicios de visitador, primero, en la chancillería de Valladolid, y la Universidad de Salamanca en 1538, luego en la chancillería de Granada (en 1539), y unos años más tarde de nuevo en la de Valladolid $^{77}$. Por ello mereció una carta de agradecimiento del emperador, que conservaba en 1648 su biznieto avecindado en Granada, Juan de Córdoba, caballero de Calatrava ${ }^{78}$.

Después de hospedar en su casa y tratar a los primeros jesuitas que pasaron por Córdoba se convirtió en protector de la Compañía y fundó el colegio de Santa Catalina ${ }^{79}$. También costeó la impresión en Córdoba en 1557, de una colección de las cartas que enviaban los jesuitas de las Indias Orientales a sus compañeros de Portugal, y que éstos copiaban y remitían a las otras provincias, en concreto a Andalucía. Mandó uno de los ejemplares de esa edición a su sobrino el III duque de Sessa, recomendándole la Compañía de Jesús ${ }^{80}$.

En su madurez intentó compensar los vicios de la juventud con obras de caridad, especialmente para con los huérfanos, pasando de 135 los que se criaron y educaron a su costa, movido por un grave suceso que presenció: había sido clausurado un hospicio fundado hacia 1400 cerca de la parroquia de San Juan de los Caballeros, por lo que los niños abandonados eran depositados en unas cunas instaladas en las galerías del patio de los Naranjos de la mezquita-catedral, para mover la compasión de la gente para que se los llevaran para adoptarlos. Iba un día D. Juan a maitines y oyó el llanto de un niño abandonado en una de esas cunas, y lo ignoró, pero, a la vuelta lo vio comido por los cerdos que campaban libremente ${ }^{81}$. Movido por la compasión y la culpabilidad, en 1561, el deán recogió a todos los niños expósitos en las llamadas "casas del agua" 82 , frente a la catedral, probablemente, las que antes había ocupado interinamente el colegio jesuita. En 1586 su so-

\footnotetext{
la Sociedad de Bibliófilos Españoles, Madrid, 1949; después, como tercera edición, por Francisco Baena Altolaguirre, por Cajasur, Córdoba 2003. Pedro Ruiz Pérez, «Casos notables de la ciudad de Córdoba. Espacios de la diferencia en la narrativa barroca», Glosa: Anuario del departamento de filología española y sus didácticas 5 (1994): 169-201.

${ }^{77}$ Antonio José Díaz Rodríguez, «Córdoba, Juan de»; también, comunicación personal del autor.

${ }^{78}$ Santibáñez, «Historia...», parte $1^{\text {a }}$, libro $1^{\circ}$, cap. 39.

${ }^{79}$ Escritura de donación y fundación dada en Córdoba, el 24 de enero de 1554: Archivo Histórico Provincial de Córdoba [AHPC] leg. 16.802-P. ff. 41r. al 54v; Antonio José Díaz Rodríguez, «El Colegio de Santa Catalina de Córdoba: notas sobre su documento fundacional», Ámbitos. Revista de estudios de Ciencias Sociales y Humanidades 19 (2008): 93-103.

${ }^{80}$ Santibáñez, «Historia...», parte $1^{\text {a }}$, libro $1^{\circ}$, cap. 40.

${ }^{81}$ Roa, «Historia...», libro 1, cap. 5.

${ }^{82}$ Luis M. ${ }^{a}$ Ramírez de las Casas-Deza, Indicador cordobés. Manual histórico-topográfico de la ciudad de Córdoba (Córdoba 1856), 400; Ramírez de Arellano, Paseos por Córdoba, 581. Después veremos que es controvertida la denominación de las casas del agua.
} 


\section{SAn Juan de Ávila y la llegada de los Jesuitas a CóRdoba, Andalucía}

brino, el obispo Pacheco, los trasladó al Hospital de Nuestra Señora de la Consolación ${ }^{83}$.

Realizó varios testamentos, y murió bajo el otorgado el 1 de agosto de 1565 ante el escribano Juan de Clavijo ${ }^{84}$, fundando un mayorazgo en cabeza del mayor de sus hijos naturales. Falleció en Córdoba, el 29 del mismo mes, noticia comunicada por el obispo Cristóbal de Rojas y Sandoval, a Francisco de Borja. Dejó como sucesor en el deanato a su sobrino D. Francisco Pacheco de Córdoba ${ }^{85}$, a quien el cabildo dio posesión el 30 de agosto de 1565, que será presentado en 1573 por Felipe II para la sede malagueña.

D. Juan era muy rico, si bien es difícil calcular con exactitud la cuantía de su renta anual líquida, ya que ésta varió a lo largo de los años, dependiendo de múltiples factores, entre ellos la productividad agrícola. El jesuita Bartolomé Bustamante la valora en 10.000 ducados de renta ${ }^{86}$, y Jerónimo $\mathrm{Nadal}^{87}$ en 12.000. De hecho, en el testamento de 1555 deja a su hijo don Juan Fernández de Córdoba diez mil ducados de oro sobre estos bienes ${ }^{88}$. Antonio José Díaz Rodríguez ha estudiado muy bien sus propiedades:

Era titular del señorío de Rute, conformado por los términos de esta misma villa y de Zambra. En ambos gozaba de jurisdicción civil y criminal y poseía, como bienes amayorazgados, tierras, derechos y diversas instalaciones industriales: huertas, monte cerrado al ganado quizás para su explotación forestal y tal vez cinegética, el cortijo del Cerro de la Higuera y el de Mata de Tora, toda la hierba de ambos términos para pasto de sus ovejas o del que pagara por ello, las ubadas ${ }^{89}$ de Rute, Torre de Zambra y Linares, los molinos de Beudera, un mesón, el horno viejo... A esto hay que sumar sus bienes particulares, no vinculados: el cortijo y dehesa del Pamplinar, las tierras de nueva labranza abiertas por él, un majuelo, varias heredades de otro tipo, un batán, unas tenerías, un horno nuevo y una almazara. Tan sólo el Pamplinar, el majuelo, el horno nuevo, el batán y las tenerías tenían un valor de al menos 3.750 .000 maravedís hacia 1555.

${ }^{83}$ Germán Saldaña Sicilia, «Monografía Histórico-Médica de los Hospitales de Córdoba», Boletín de la Academia de ciencias, Bellas Letras y Nobles Artes de Córdoba XIV (1935): 22-32.

${ }^{84}$ Había otorgado dos testamentos en enero y marzo de 1550 (AHPC, 16.797-P, fols. 1.413r. y ss.). Otro testamento realizó en 1554 (AHPC, 16.802-P. ff. 1r.-17v,) seguido de varias escrituras con el colegio, aparte de la donación misma, la toma de posesión del edificio del colegio por la Compañía (57r.-58v.), el documento público de consagración y dedicación de la iglesia del colegio (62r.-63v.), la donación y toma de posesión de unas casas en la calle trasera (Gilete), etc. Un nuevo testamento está fechado en 1555 (AHPC, 16.804-P, 1.360r-1.373v.) y, finalmente, el testamento de 1 agosto 1565: (AHPC, 12.853-P).

${ }^{85}$ Cristóbal de Rojas obispo de Córdoba a Francisco de Borja, Toledo 23.10.1565, Borgia IV, 113.

${ }^{86}$ Bartolomé Bustamante a Ignacio de Loyola, Córdoba 31.10.1553, EppMixtae III, 574-575.

${ }^{87}$ Jerónimo Nadal a Ignacio de Loyola, Valladolid, 15.03.1554, Natalis I, 227.

${ }^{88}$ AHPC, 16.797-P, 1.360r-1.373v.

${ }^{89}$ Medida agraria equivalente a 36 fanegas. 


\section{Wenceslao Soto Artuñedo, S.J.}

Otras ganancias de gran importancia procedían de sus prebendas. Al sustancioso salario de deán se han de añadir los de canónigo doctoral, capellán mayor o abad de Rute y beneficiado de Cabra. Todo ello complementado con los frutos de las prebendas que, con su poder e influencia, había obtenido para clientes y familiares, bien directamente o a base de gravar éstas con pensiones, generalmente de una tercera parte ${ }^{90}$.

Por último, sus ingresos se veían completados por una serie de inversiones, tanto en Córdoba como en Baena y en Rute, donde poseía varias casas: bienes rústicos, compraventa y arrendamiento de inmuebles urbanos, censos, juros, oficios.

La suma de las donaciones que hizo al colegio jesuita, entre casas, biblioteca, joyas, censos y otros bienes, llegaba a 30.000 ducados, además de la manutención de los jesuitas por 12 años. En algún momento había expresado su deseo de dejar al colegio todos los bienes, pero, de hecho, fundó un mayorazgo con ellos para su hijo D. Juan de Córdoba, y nombró al colegio heredero en caso de que faltase sucesor legítimo. Su renta era de 3.000 ducados en el año 1643 en que Juan de Santibáñez escribe la "Historia de la Provincia de Andalucía"91.

Beatriz Mejía fue su amante preferida y madre, al menos, de su primogénito, pero fue alejada de su vida, tras entrar en contacto con los jesuitas. En 1555 la encontramos viviendo en Rute en una casa propiedad del deán, y mantenida por él. En su testamento se acuerda de ella:

A Beatriz Mejía, por el cargo en que le soy y por el servicio que ha fecho en mi casa, que por los días de su vida posea y tenga el usufructo del horno nuevo que yo tengo en mi villa de Rute, y las casas en que vive, y la roza que se compró del Pino en término de Zambra, y la viña que se compró de Alonso García, mesonero. Todo lo cual la dicha Beatriz Mejía tenga y posea y lleve los frutos y rentas de ellos, todos los dichos días de su vida, y aquellos cumplidos vuelvan los dichos bienes y los haya don Juanico de Córdova, hijo de la susodicha. Y demás de esto, mando que le den a la dicha Beatriz Mejía un aderezo de cama y casa que valga hasta en contía de cuarenta mil maravedís. Y más le den cincuenta mil maravedís en dineros. Y demás de esto, se le den en cada un año de los dichos días de su vida cuarenta hanegas de trigo, las cuales asi(g)no que las aya sobre mi cortijo, tierras y heredamientos que dicen del Pamplinar, como adelante se diráa ${ }^{92}$.

Tuvo más de seis hijos naturales. El primogénito fue Juan Fernández de Córdoba, caballero de Santiago, comendador de Oliva, señor del mayorazgo

\footnotetext{
${ }^{90}$ Antonio J. Díaz Rodríguez, «Las casas del deán don Juan de Córdoba: lujo y clientela en torno a un capitular del renacimiento», Hispania Sacra LXI (2009): 77-104.

${ }^{91}$ Santibáñez, «Historia...», parte $1^{\text {a }}$, libro $1^{\circ}$, cap. 39.

${ }_{92}$ Testamento de 1550, en AHPC, 16.797-P, fols. 1.413r. y ss, citado por Díaz Rodríguez, «Las casas...», 77-104.
} 


\section{SAn Juan de Ávila y la llegada de los Jesuitas a CóRdoba, Andalucía}

fundado en él por su padre ${ }^{93}$, casado en Granada con Antonia de Bernúy y Barba, hija segunda de Diego de Bernúy y Orense de la Mota (Señor de Benamejí), y de Guiomar Barba de Acuña y Cusanza. Por testamento de su padre recibía diez mil ducados de oro sobre sus bienes ${ }^{94}$. Francisco de Borja le pidió un donativo para la construcción de la iglesia del Gesú en Roma ${ }^{95}$. Cuando murió, se le celebraron unas exequias solemnes y fue sepultado en una cripta debajo del presbiterio de la iglesia del colegio jesuita de Córdoba y su viuda pidió que cuando se celebrara el aniversario de su suegro, el fundador, se realizase otro de su difunto marido y el P. General respondió concediéndoselo, pero parcialmente "puesto que no se le puede negar", sólo mientras ella viviera y estando a cargo de sacerdotes no jesuitas ${ }^{96}$.

Otro hijo suyo, Gabriel de Mendoza, fue dominico en el convento de San Pablo, de Córdoba. Luis de Córdoba o Luis de la Cerda, el Bayo ${ }^{97}$, fue canónigo y arcediano de Madrid en la catedral de Sigüenza. Leonor de Córdoba fue casada con su primo Martín Fernández Venegas, heredero del mayorazgo de la rama segundona de los señores de Luque, Egas Venegas de León y Elvira Manuel de Lando y Guzmán ${ }^{98}$.

Otras tres hijas fueron monjas en el convento de Santa Inés, de Córdoba: Juana de la Cerda, Bárbara de Córdoba, y Juana de Córdoba. También pudieron ser hijas suyas Francisca de San Pedro Mártir y María de la Cruz, monjas en el convento de Madre de Dios de Baena, fundación del padre de D. Juan de Córdoba en 1510, que desde el principio se convirtió en salida idónea para muchas de las hijas extramatrimoniales de los miembros de la Casa de Cabra. De ellas se acordó en su testamento y las dotó para profesar ${ }^{99}$.

\footnotetext{
${ }^{93}$ Heredó el mayorazgo su hijo Luis Fernández de Córdoba y Bernúy, casado en primeras nupcias con Mariana de Pisa Osorio, y en segundas nupcias con Ana María de Mendoza, su prima hermana, hija de Diego IV de Bernúy, III Señor de Benamejí. Luis tuvo dos hijas del primer matrimonio: Guiomar de Córdoba y Pisa, casada con su tío Iñigo de Bernúy Mendoza, sin sucesión; Ana María de Córdoba y Pisa, heredera del mayorazgo de Pisa, casada con su tío, Antonio Fernández de Córdoba, I marqués de Valenzuela. Otra tercera hija de su segundo matrimonio fue Luisa Jacinta de Córdoba y Mendoza, que murió soltera.

${ }^{94}$ AHPC, leg. 16.797-P.

${ }^{95}$ Francisco de Borja a Diego de Avellaneda, Roma 12.10.1568, Borgia VI, 661.

${ }^{96}$ ARSI, Baet. 3-I, 72, Acquaviva al Provincial, 03.08.1592; 74: A Doña Antonia de Bermi Barba, en Granada, 03.08.1592: le dice que remite el asunto del aniversario al Provincial.

97 "Dicho especialmente de un caballo y de su pelo: De color blanco amarillento", Real Academia Española: Diccionario de la lengua española, 23. ${ }^{a}$ ed., [versión 23.4 en línea]. <https://dle.rae.es> [31.10.2021].

${ }^{98}$ Tuvieron tres hijos: Egas Manuel de Lando, y Córdoba, muerto sin sucesión; María Venegas de Córdoba, casada con Garci-Suárez de Carvajal, II Señor de las villas de Peñalver y Alhóndiga, sin sucesión; Francisca Venegas de Córdoba, casada con su primo Antonio Fernández de Córdoba VIII Señor de la villa de Guadalcázar, sin sucesión.

${ }^{99}$ Díaz Rodríguez, «Las casas...», 77-104.
} 


\section{Wenceslao Soto Artuñedo, S.J.}

D. Juan tenía establecida su Casa en Córdoba, y a ella pertenecían entre otros, el arcipreste de Alcaraz, D. Diego Pérez de Alarcón, y el beneficiado Alonso de Tejada, Diego de San Juan, beneficiado de la vecina parroquia del Salvador y primo hermano de Francisco de Toledo, cardenal jesuita. También era de su casa Alejo de Cardeña, quien en 1556 corrió con los gastos de impresión (si bien quien de verdad debió de pagar los costes fue el deán) del libro De utraque copia, verborum et rerum praecepta vna cum exemplis dilucido breuique carmine comprehensa ... (Córdoba, 1556), obra del jesuita André des Freux, un manual para el colegio de los jesuitas en Córdoba ${ }^{100}$.

$\mathrm{Su}$ residencia abarcaba un enorme solar comprendido entre la actual Plaza de la Compañía y las calles Duque de Hornachuelos (entonces del Paraíso), Juan de Mena (conocida como de Gilete, Jilete, Filete o Hilete), y Juan Valera (en aquel tiempo calle del Marqués de la Guardia). Una parte de su casa, varias piezas auxiliares y una parte de la huerta, fueron donadas a la Compañía de Jesús para la fundación del colegio de Santa Catalina, segregando para sí otra parte de sus propiedades, para su nueva vivienda ${ }^{101}$.

Antonio J. Díaz Rodríguez ha descrito cómo sería su residencia, una vez que redujo su tamaño tras la donación para el colegio de la Compañía, utilizando el inventario realizado tras su muerte, en 1565, completado con otros documentos. A través de las puertas principales se accedía a un zaguán, que daba paso al patio principal, en torno al cual se estructuraba la mayor parte de la casa. Había una zona de servicio, más próxima a la entrada y otra más privada e interior.

A uno y a otro lado de este espacio recibidor se encontraban una pequeña botillería o bodega y las caballerizas respectivamente, y pasando las caballerizas, se entraba en otra botillería de la mansión.

En el patio principal, pero aún en la zona de servicio, hallamos, junto a los dos pozos de los que, como mínimo, disponía la vivienda, sendas piezas destinadas al almacenamiento de comestibles. Una de ellas, junto al segundo pozo, estaba subdividida en dos cuartillos, que llaman "botillería", donde en realidad se guardan tres tinajas de aceitunas, y enfrente algo similar a un trastero. Cerca de la despensa parece que había estado la cocina.

De nuevo desde el patio principal, se pasa a la zona noble o privada del palacio: una sala grande a mano izquierda, con ventanas a la actual calle de

\footnotetext{
${ }^{100}$ Díaz Rodríguez, «Las casas...».

${ }^{101}$ Díaz Rodríguez dice que la donación a la Compañía consistió en casi un tercio del antiguo solar de sus casas, el que antes ocuparan unas grandes caballerizas, pero parece que la cantidad donada fue mayor, pues solo el solar de las caballerizas se preveía usar para la iglesia, debiendo haber otro espacio para la residencia de la comunidad, cf. Documento de donación del colegio de Córdoba, ante Alonso de Toledo, 24 de enero de 1554, ARSI, Fondo Gesuitico [FG] 1404/4, 3.
} 


\section{SAn Juan de Ávila y la llegada de los Jesuitas a CóRdoba, Andalucía}

Santa Victoria. Había otra similar a mano derecha, con tapices. Una cuarta crujía cerraba el patio por el lado occidental, ocupada por el corredor decorado por un árbol genealógico de la Casa de Córdoba. Desde aquí se accedería a la planta superior, al jardín y a la capilla y sacristía, con abundancia y riqueza de objetos litúrgicos.

La sala que daba a la calle parece que se trata de un enorme comedor para banquetes, que podía dividirse en dos espacios más pequeños y útiles para el uso cotidiano gracias a una mampara.

Del inventario puede deducirse la existencia de otra crujía adosada a la que ocupaba la sala de los tapices. En ella se encuentra el trascuarto, o sala de estar, cuya puerta daba seguramente a un segundo patio, más interior y colindante con las dependencias cedidas a la Compañía de Jesús.

En el piso superior se contabilizaban hasta nueve dormitorios. Las dependencias de D. Juan estaban formadas por una cámara, una recámara donde dormía un criado, Clemente de Rojas o bien un paje, y un estudio.

La casa disponía de un jardín cerrado, con huertas con una noria de bestia para sacar agua, que dejará al Colegio de Santa Catalina ${ }^{102}$.

Dadas sus donaciones cuantiosas, san Ignacio pidió a Villanueva ${ }^{103}$ y Borja que buscasen la mejor forma para reconocerle su aportación al colegio:

Acá nos hemos gozado mucho en el Señor nuestro del spiritu y liberalidad del Sr. D. Joán de Córdoba, que se paresçe bien la mano de Dios N. S., que obró en su ánima, y la buena disposición della para rescibir tal impressión. De todo sea gloria al auctor de todo lo bueno en sus criaturas. Mucho nos obliga su deuoción tan liberal y sincera á procurar de reconosçerla en el modo mejor que á nosotros sea possible; y quál deba ser este, querria entender vuestro pareçer; aunque el verdadero reconoçedor es Dios N. S., por cuyo amor se ha mouido á esta tan buena obra, y de quien habrá el verdadero premio della ${ }^{104}$.

A la hora de la muerte se acuerda también de la Compañía, pide el reconocimiento como fundador del colegio y nombra sucesor suyo, para esto, al duque de Baena y sus sucesores:

Por cuanto con el ayuda de Ntro. Señor yo fundé e hice en su servicio este colegio del Nombre de Jesús de esta ciudad de Córdoba, y les he dado en mi vida e ayudado, e ahora en este mi testamento le doy todo lo que he podido y puedo e de esto yo no les dejo carga ni obligación más de la que ellos se tienen de rogar a Dios por mí y ellos en reconoscimiento de la buena obra y servicio

\footnotetext{
${ }^{102}$ Díaz Rodríguez, «Las casas...», 77-104; Ver también Raúl Molina Recio, La nobleza en la España Moderna: los Fernández de Córdoba. Familia, riqueza, poder y cultura, (Tesis doctoral Universidad de Córdoba 2004). https://helvia.uco.es/xmlui/handle/10396/6269.

${ }^{103}$ Ignacio a Villanueva, 08.03.1554, EppIgn. VI, 437.

${ }^{104}$ Ignacio a Borja, 08.03.1554, EppIgn. VI, 432.
} 


\section{Wenceslao Soto Artuñedo, S.J.}

que a Ntro. Señor se ha hecho, como a fundador dan una vela de cera el día de San Juan en cada un año perpetuamente, labrada con las armas de la Casa de Baena, e porque no se pierda esta memoria soy obligado a señalar subcesor a quien se dé e haga este reconoscimiento, digo e declaro que esta vela se dé perpetuamente al duque mi señor e a sus subcesores en el condado de Cabra e Casa de Baena, y le suplico por amor de Ntro. Señor que ansí su Excelencia como los que le subcedieren miren mucho por este colegio e por los padres y hermanos de él e les favorezcan en todo lo que les subcedieren pues yo nombro a su Excelencia e a sus subcesores por patrones de una casa tan señalada como es este colegio ${ }^{105}$.

Quedó, así, el patronato del colegio en poder de los duques de Sessa, condes de Cabra, señores de Baena y otras villas y estados, sobrinos de D. Juan ${ }^{106}$.

\section{Fundación del colegio de Córdoba}

\subsection{Punto de partida: San Juan Ávila y el Ayuntamiento}

\section{Colegio en la collación de Santiago}

El primer proyecto de colegio jesuita en Córdoba es una evolución de una iniciativa de san Juan de Ávila y su insistencia con el Ayuntamiento para que apoyara financieramente este centro cultural ${ }^{107}$.

S. Juan de Ávila había iniciado una escuela en 1539 en la collación de Santiago, junto a la puerta de Baeza, probablemente en la calle de las Siete Revueltas ${ }^{108}$. Para garantizar suficiente financiación por parte de una entidad solvente, también interesada en el mismo objetivo, acudió al Ayuntamiento el 22 de septiembre de 1540. Informó que él ofrecía un beneficio suyo en Santaella, y pedía que el Ayuntamiento añadiera alguna aportación, además de señalar el sitio y ayudar a la obra. La Ciudad accedió y nombró una comisión para localizar un lugar adecuado y buscar una renta de 100.000 maravedís ${ }^{109}$.

\footnotetext{
${ }^{105}$ Testamento q de agosto 1565: AHPC, 12.853-P.

${ }^{106}$ El P. General al Provincial, 25 abril 1566, ARSI, Hisp. 67, 164.

${ }^{107}$ Wenceslao Soto Artuñedo, «San Juan de Ávila y la Compañía de Jesús. La fundación del colegio de Córdoba», en Vida y obra de San Juan de Ávila. Actas II Congreso Internacional San Juan de Ávila, Córdoba 21 al 23 de noviembre 2019, ed. por Manuel Pérez Moya y Antonio Llamas Vela (Córdoba: Almuzara, 2021), 143-184.

${ }^{108}$ Juan Aranda Dondel, «San Juan de Ávila y el clero diocesano cordobés durante los siglos XVI al XVIII», en San Juan de Ávila, doctor de la Iglesia. Actas del Congreso Internacional, ed. por Juan Aranda Doncel y Antonio Llamas Vela (Córdoba: Diputación, 2013), 157-201.

${ }^{109}$ Constan gestiones, al menos, en los cabildos de 1540, 1543, 1548, 1550 y 1551.
} 


\section{San Juan de Ávila y la llegada de los Jesuitas a CóRdoba, Andalucía}

El 27 de septiembre confirmó la concesión de 100.000 maravedís de unos baldíos ${ }^{110}$, pero estos acuerdos fueron recurridos por los jurados de baldíos, al rey, que mandó por una provisión real de 14 de diciembre de 1540 paralizar el asunto hasta recibir mayor información en el plazo de 15 días ${ }^{111}$. Puesto que el tema quedó sin resolver, de nuevo, el 10 de septiembre de 1548 volvió a insistir. El cabildo nombró una comisión con amplios poderes para acordar lo necesario, e incluso varios de los veinticuatros ofrecieron generosamente sus salarios por diez años para que la obra llegase a término ${ }^{112}$. Finalmente, dispuso "para principio de aquello" 550.000 maravedís de las sobras ${ }^{113}$ del encabezamiento ${ }^{114}$ general del reino ${ }^{115}$, por lo que Ávila pidió el 14 de enero de 1550 que se entregase ese dinero al colegio, y fue consumido en sueldos de maestros, sin invertir nada ${ }^{116}$.

\section{Ofrecimiento a la Compañía}

Estando el colegio en esa situación, y sintiéndose el maestro muy enfermo, ofreció sus escuelas, especialmente la de Córdoba, con sus discípulos, a la Compañía, una vez que supo la intención de su discípulo Antonio de Córdoba, ya jesuita, de realizar una fundación similar. Así, antes de diciembre de 1552 escribió al provincial jesuita Antonio Araoz, de lo que se hace eco una carta de Borja a Ignacio desde Vergara, el 6 diciembre de 1552: "estando muy enfermo quiere dejar por heredera a la Compañía de sus discípulos en los colegios". Pide una visita del provincial o alguien autorizado, $y$, puesto que el proyecto

${ }^{110}$ Se denomina "bien baldío" al terreno urbano o rural sin edificar o cultivar que forma parte de los bienes del Estado porque se encuentra dentro de los límites territoriales y carece de otro dueño. Los bienes baldíos son imprescriptibles, es decir que no son susceptibles de adquirirse en proceso de pertenencia por prescripción adquisitiva de dominio.

${ }^{111}$ AMC Actas Capitulares, 22 y 27 septiembre 1540; Sala, Obras completas, 84-85.

112 AMC, Actas Capitulares 10 septiembre 1548, Sala, Obras completas, 121.

${ }^{113}$ Las sobras eran el beneficio fruto de la diferencia entre el valor del encabezamiento, o cantidad comprometida con la real hacienda y el producto del arrendamiento efectuado por el municipio entre particulares.

${ }^{114}$ Los encabezamientos o asientos, son un sistema de recaudación de impuestos de la Edad Moderna. Consistía en alquilar los impuestos al mejor postor, con lo que la Corona se aseguraba unos ingresos mínimos, mientras que quien alquilaba adquiría el derecho de cobrar todos los impuestos correspondientes a una determinada zona.

La recaudación de todos los impuestos de todos los territorios suponía más gastos que ingresos, por eso se inventó el sistema de encabezamientos, o alquiler del derecho de recaudación. Los que consiguen un encabezamiento, tras subasta, son llama arrendadores mayores. Los encabezamientos aparecen en los primeros años del siglo XVI y se subastaba en los territorios. En 1534 se subastó en todo el reino el encabezamiento general, pero no fue suscrito hasta el 15 de agosto de 1536.

${ }^{115}$ AMC, 10 de enero 1550, Obras completas (1952): 129.

${ }^{116}$ Cabildo de 22 de junio, Obras completas (1952): 133. 


\section{Wenceslao Soto Artuñedo, S.J.}

recibe el visto bueno de D. Antonio y de los que conocían Andalucía, Borja se ofrece a ir si no se lo impidieran "unas cuartanas"117.

A finales de 1552 el maestro envió a Alcalá de Henares a sus discípulos Gaspar Loarte y Diego Guzmán ${ }^{118}$, con intención de entrar en la Compañía. Al no encontrarse allí Araoz, fueron remitidos a Francisco de Borja, en Oñate ${ }^{119}$, donde ingresaron en la Compañía. Araoz escribió a Juan de Ávila el 19 de enero de 1553, excusándose por no haber podido recibir a sus discípulos en Alcalá, al tiempo que le explicaba la escasez de sujetos y la poca salud de Francisco de Borja para viajar, de momento, a Córdoba, pero asumía el tema de los colegios, si bien, creía que, antes, debía conocerlos ${ }^{120}$.

El ofrecimiento de Ávila llegaba en un momento muy oportuno, en el que la Compañía, después de las primeras experiencias, había evolucionado hacia un concepto de colegio iniciado en Gandía y perfeccionado en Messina y en Roma donde se formasen jesuitas (colegio) y también externos (escuelas) ${ }^{121}$, modelo que san Ignacio pretendía implantar también en España ${ }^{122}$, con el objetivo era formar en virtud y letras ${ }^{123}$.

\subsection{Primer proyecto del colegio jesuita: La casa de Aguilar}

D. Antonio de Córdoba

D. Antonio, por su parte, ya desde su admisión en la Compañía en mayo de 1552, tenía la intención de fundar un colegio en Córdoba ${ }^{124}$, ofreciendo para ello las rentas de sus beneficios eclesiásticos. La marquesa aprobaba la idea que le expresó su hijo, inclinándose por que la fundación fuese en la ciudad de Córdoba, tanto por la obligación de D. Antonio a esta ciudad, como por ser los beneficios a permutar de la misma ciudad. Pide a su hijo que le escriba informándole de cuánta renta sería necesaria, para cuántos sujetos, y cómo se podría hacer la permuta de los beneficios eclesiásticos ${ }^{125}$. $\mathrm{D}^{\mathrm{a}}$. Catalina no

\footnotetext{
${ }^{117}$ Borja a Ignacio, Vergara, 6 diciembre de 1552, Borgia III 120.

${ }^{118}$ Don Diego Ponce de León y Guzmán, hermano del II conde de Bailén, don Manuel Ponce de León y Guzmán.

${ }^{119}$ Dionisio Vázquez a Ignacio de Loyola, Alcalá de Henares 01.01.1553, Litterae Quadrimestres ex universis praeter Indiam et Brasiliam locis, in quibus aliqui de Societate Iesu versabantur. 7 vol., Madrid 1894-1932 [en adelante LittQuad.], IV, 645.

${ }^{120}$ Antonio de Araoz al Maestro Juan de Ávila, Alcalá 19.01.1553, EppMixtae III, 67-70.

${ }^{121}$ Wenceslao Soto Artuñedo, «El apostolado ignaciano de la educación: Institutio puerorum para la reformatio mundi», Manresa. Revista de Espiritualidad Ignaciana 89/353 (2017): 317-328.

${ }^{122}$ EppIgn IV, 9-11; Polanco (ex comm.) a Araoz. Roma, $1^{\circ}$ diciembre 1551 (1). EppIgn IV, 5-9

${ }^{123}$ Medina, «El proceso fundacional».

${ }^{124}$ Ignacio de Loyola a Gaspar de Doctis, Roma, 10.09.1552 EppIgn. IV, 429.

${ }^{125}$ Catalina Fernández de Córdoba a su hijo el P. Antonio de Córdoba, Córdoba agosto 1552, EppMixtae, $\mathrm{V}, 758$. No obstante, después quiso que D. Antonio resignase su canonicato en un muchacho
} 


\section{SAn Juan de Ávila y la llegada de los Jesuitas a CóRdoba, Andalucía}

ocultaba sus esperanzas de que el colegio ayudase a acoger a conversos y a regenerar la iglesia cordobesa ${ }^{126}$.

La marquesa creía que la casa que la familia tenía en Córdoba no era adecuada, y además, estaba vinculada a un mayorazgo, pero su administrador pensaba que esa casa era buen sitio para lo que se pretendía ${ }^{127}$. En ese tiempo, la marquesa se encontraba apurada por deudas y debía tener en cuenta las necesidades de sus hijos tras la muerte de su marido. Por ello, el P. Miguel de Torres, rector de Salamanca, reconocía que los hermanos de D. Antonio eran "pobres de hacienda y aventajados en sus pensamientos", con peligro de hacerse dependientes del hermano si éste aceptaba el capelo cardenalicio que se le preparaba ${ }^{128}$. El déficit financiero de la marquesa ${ }^{129}$ obligaba a pivotar la fundación sobre las rentas eclesiásticas de D. Antonio, mientras que, por su parte, la madre ofrecía alguna ayuda con la condición de que la ciudad aplicase a este colegio los maravedíes del encabezamiento, que ya había cedido al estudio del maestro Ávila ${ }^{130}$.

D. Antonio escribió a S. Ignacio el 22 de septiembre de 1552, con el mismo ofrecimiento de la renta de la canonjía y la dignidad de maestrescolía que tenía en Córdoba, por valor de unos 1.000 ducados, e informaba que se estaba tramitando en España la permuta en beneficios simples que se pudieran unir al colegio, para lo que ayudaría alguna gestión ante la Penitenciaría, en Roma ${ }^{131}$.

San Ignacio dio su bendición el 27 de enero de 1553, al tiempo que le indicaba a D. Antonio que para procurar la anexión, la marquesa debía escribir a su agente en Roma, con carta del príncipe ${ }^{132}$. Así, el colegio de Córdoba quedaba pendiente de la permuta de la canonjía y dignidad de D. Antonio por préstamos $^{133}$ o beneficios simples ${ }^{134}$ que se pudieran anexar ${ }^{135}$.

sobrino suyo, lo que él pensaba que no podía hacer por ser menor, Antonio de Córdoba a Juan de Polanco, Salamanca 29.12.1554, EppMixtae IV, 488-494.

${ }^{126}$ Marquesa de Priego a Antonio de Córdoba, agosto 1552, EppMixtae III, 759.

${ }^{127}$ Marquesa de Priego a Antonio de Córdoba, agosto 1552, EppMixtae V, 758.

${ }^{128}$ Torres a Ignacio, Salamanca, 28, 30 marzo 1552. EppMixtae II, 695.

${ }^{129}$ Consecuencia de los gastos que exigía el servicio real, provenientes de las empresas exteriores y levantamientos internos pasados, pues su familia, junto con otras nobles de Andalucía, había formado parte de la liga antifernandina opuestos a la gobernación de Castilla por el "rey de Aragón" (Fernando el Católico), en lugar de su hija doña Juana, a quien acataban como única y legítima soberana, Medina, (1994) 3-75.

${ }^{130}$ Medina, «El proceso fundacional».

${ }^{131}$ Antonio de Córdoba a Ignacio de Loyola, Oñate, 22.09.1552, EppMixtae, II, 788-790.

${ }^{132} \mathrm{Al}$ P. Antonio de Córdoba, Roma 27.01.1553, EppIgn. IV, 615.

${ }^{133}$ Viene de "prestamera", y se refiere a un estipendio o pensión procedente de rentas eclesiásticas que se daba temporalmente a los que estudiaban para sacerdotes o a los que militaban por la Iglesia, y que después se convirtió en una especie de beneficio eclesiástico.

${ }^{134}$ En ellos el beneficiado no asume deberes de la iglesia ni obligaciones pastorales, como ocurre en los beneficios dobles. Son también beneficios no residenciales y compatibles.

${ }^{135}$ Borja a Ignacio, 28.02.1553, Borgia III, 134; Antonio de Córdoba a Ignacio de Loyola, Oñate, 


\section{Wenceslao Soto Artuñedo, S.J.}

\section{Ayuntamiento}

Ávila comprendió que la entrada de la Compañía en Córdoba era la única solución viable a su colegio, para crear un gran centro cultural contando con la financiación que el Ayuntamiento había cedido para su estudio, a lo que se añadirían los beneficios de D. Antonio y la aportación de la marquesa. De este modo confluyeron los dos proyectos, el de san Juan de Ávila/Ayuntamiento (escuelas para el público) y el de la casa de Aguilar (colegio para jesuitas), integrándose la financiación del ayuntamiento con la que ofrecía la casa de Aguilar para fundar un colegio donde se formaran jesuitas, que contendría también una escuela pública.

De estas novedades informó Ávila al Ayuntamiento, el 18 de marzo de 1553, y el cabildo se comprometió a ceder las sobras del encabezamiento general del reino de tercias ${ }^{136}$ y alcabalas ${ }^{137}$, para la construcción de las escuelas públicas en el nuevo colegio que se fundara.

Supuesta la información verbal, Ávila y la marquesa presentaron por escrito al cabildo cordobés la propuesta de D. Antonio, que se leyó el 12 de abril de 1553, y después de comentarla, se despacharon a Montilla dos caballeros veinticuatro ${ }^{138}$. Vueltos de Montilla el 19 de abril, traían la respuesta de la marquesa confirmando el ofrecimiento de sus Casas del Agua para el colegio y pedía que el Ayuntamiento determinase el sitio para las escuelas, por lo que se convocó cabildo general para el 21 de abril. El cabildo del 21 de abril tiene su importancia, no sólo por ser donde se aprobó la fusión de proyectos, sino por el debate que lo precedió sobre el uso de fondos públicos para financiar una iniciativa privada, o una iniciativa social para un servicio público, según diríamos hoy. Finalmente, la resolución del cabildo fue apoyar la creación del colegio de los jesuitas en las Casas del Agua y construir unos estudios generales adosados a él. Se comunicó a la marquesa y leída su respuesta afirmativa el 8 de mayo, se acordó trazar los planos, nombrando

04.05.1553, EppMixtae III, 285.

${ }^{136}$ Las tercias reales son un ingreso concedido por la Iglesia a la Corona consistente en dos novenos de los diezmos eclesiásticos recaudados por la misma y que se llegó a convertir en un ingreso habitual de la Corona.

${ }^{137}$ La alcabala fue el impuesto más importante del Antiguo Régimen en la Corona de Castilla y, desde luego, el que más ingresos producía a la hacienda real — pues aunque el diezmo era aún más importante, su perceptor principal era la Iglesia, con participación del rey-. A pesar de que aparentemente era un impuesto indirecto que gravaba las compraventas y todo tipo de transferencias (era pagado por el vendedor en la compraventa y por ambos contratantes en la permuta), su compleja administración hace que tuviera muy poco que ver con el actual sistema del IVA.

138 Archivo Municipal Córdoba [AMC], Cabildo de 12 de abril 1553, Sala, Obras completas, (1952), 148-150. "Dadas estas cartas y reçivida respuesta diputó la çiudad a Juan de Valençuela y a don Pedro Muñoz de Godoy de los ventiquatro cavalleros de su govierno, para que en su nombre fuessen a Montilla y tratassen a boca de este negoçio con la Marquessa", Roa, «Historia», cap. 3. 


\section{SAn Juan de Ávila y la llegada de los Jesuitas a CóRdoba, Andalucía}

diputados para ello ${ }^{139}$. Estas decisiones fueron confirmadas en el cabildo general de 17 de mayo ${ }^{140}$.

Una vez que el cabildo de la ciudad resolvió su participación en la fundación, la marquesa y su hijo comenzaron a gestionar la obtención de las licencias necesarias. La una, del emperador o del príncipe, para desvincular las Casas del Agua, la otra, del papa, para la permuta de la prebenda. El príncipe otorgó la licencia a la marquesa y encargó la gestión de la permuta, con cartas comendaticias, tal como san Ignacio había propuesto a D. Antonio, al nuevo embajador del emperador en Roma, Fernando Ruiz de Castro y Portugal, IV conde Lemos y I marqués de Sarriá. El príncipe también había escrito al papa sobre ello ${ }^{141}$.

La marquesa había prometido dar la renta suficiente para alimentar a la comunidad del colegio, además de lo que rentase la maestrescolía, mientras se producía la anexión, pues los beneficios aún no estaban anexados. Se pedía una cantidad de anexión de 800 ducados, aunque lo que se ofrecía por la maestrescolía eran 500. El Ayuntamiento ofrecía también ayuda para la manutención y aportar cerca de 3.000 ducados para la construcción de la escuela, aunque no se confiaba tanto en esto como en la promesa de la marquesa, que entregaba un buen sitio.

La casa del Agua había sido sacada del mayorazgo con permiso del príncipe, y mientras era preparada para colegio, la marquesa pensó que los jesuitas podrían instalarse en otra vivienda que tenía D. Antonio de Córdoba en usufructo. Borja esperaba mucho de esta fundación, "así por los grandes ingenios que ay en aquella tierra, como porque será entrada para toda la Andaluzía"142.

Llegada de los primeros jesuitas

Otro hijo de la marquesa, el conde de Feria, Gómez Suárez de Figueroa, se entrevistó con Araoz y "hablaron largo de las cosas del colegio que la marquesa de Priego, su madre, tiene concertado con la ciudad y cabildo de Córdova, que se haga en aquella ciudad"143. Le pedía también que la visitaran para consolarla por la pesadumbre que le causó la decisión de su nuera Ana Ponce de León, de hacerse monja, una vez viuda de su otro hijo Pedro Fernández de Córdoba y de Figueroa. Como resultado de esto, Borja decide visitarla, pero antes, pensó que sería bueno que el P. don Antonio viajase a Montilla, y lo excusara a él, que iría a Córdoba, pero pasando por Portugal, pues no

\footnotetext{
${ }^{139}$ Sala, Obras completas (1970), I, 147-152.

${ }^{140}$ AMC, Actas 8 y 17 de mayo, Sala, Obras completas (1970), 152.

${ }^{141}$ Chron III, 350-351 n ${ }^{\circ} 774$; Medina, «El proceso fundacional».

${ }^{142}$ Francisco de Borja a Ignacio de Loyola, Medina del Campo 31.07.1553, Borgia III, 148-149.

${ }^{143}$ Antonio Gou a Ignacio de Loyola, Madrid 12.05.1553, EppMixtae III, 289.
} 


\section{Wenceslao Soto Artuñedo, S.J.}

podía aplazar más la respuesta al rey Juan III, tras su tercera llamada. A don Antonio lo acompañaría el P. Villanueva, rector de Alcalá de Henares, según había acordado con el provincial, y si no estuviera curado de unas calenturas, iría el P. Diego Carrillo, también del colegio de Alcalá144. Así, Borja escribía desde Salamanca al P. Francisco Villanueva, para dar inicio a la fundación. Villanueva escribe a san Ignacio el 2 de septiembre de 1553, explicándole que ya había recibido indicaciones de Borja en dos ocasiones más sobre este asunto, $y$, que aunque él creía que debía ir otra persona más relevante, se hubiera presentado después de la primera carta, pero no pudo por una enfermedad padecida a primeros de julio. Ya, bastante restablecido, pensaba partir para Córdoba hacia mediados de septiembre ${ }^{145}$.

Borja, Bustamante, Antonio de Córdoba, y el hermano Bernardo partieron de Burgos y se detuvieron unos días en Medina del Campo donde se separaron: los dos primeros marcharon a Portugal desde Salamanca, mientras que los dos últimos anunciaron que el 11 de agosto partirían hacia Córdoba y Montilla $^{146}$.

Villanueva, por su parte, alcanzó Córdoba ${ }^{147}$ con el licenciado H. Alonso López, el 26 de septiembre de $1553^{148}$ y continuó hasta Montilla donde ya estaba D. Antonio, y fueron hospedados por la marquesa en una casa próxima a su palacio. Se entrevistó con el maestro Ávila, a quien explicó lo que era la Compañía, que recibió con gran satisfacción esas explicaciones, pues tenía cierta prevención porque le habían dicho que en los Ejercicios se forzaba a emitir votos al ejercitante, a lo que respondió Villanueva que eso estaba expresamente prohibido ${ }^{149}$.

\footnotetext{
${ }^{144}$ Francisco de Borja a Ignacio de Loyola, Salamanca 16.08.1553, Borgia III, 150.

${ }^{145}$ Francisco Villanueva a Ignacio de Loyola, Alcalá 02.09.1553, EppMixtae, III, 463.

${ }^{146}$ Francisco Estrada a Ignacio de Loyola, Burgos 08.08.1553, EppMixtae III, 422.

${ }^{147}$ Cristóbal de Castro en Historia del colegio de Alcalá, sitúa esa visita a final de 1552, (Cristóbal de Castro, «Historia del Colegio Complutense de la Compañía de Jesús», 1600, Archivo de España de la Compañía de Jesús en Alcalá de Henares), y siguiéndolo a él lo hacen también Roa («Historia», Libro 1, cap. 2) y Santibáñez que fecha la visita el 27 de septiembre de 1552 («Historia»), $1^{\text {a }}$ Parte, libro 1, cap. 13). Polanco la ubica en 1549, a raíz del primer deseo de Ignacio de que Villanueva fuese a visitar a Ávila (Chron I, no 465, 433).

${ }^{148}$ Por comisión de Manuel López, a Ignacio de Loyola, Alcalá, 31.12.1553, LitQuad II, 498-505. Santibáñez lo sitúa el 25 de septiembre de 1552 y la llegada a Montilla el día 27.

${ }^{149}$ Chron I, no 465, 433. La anotación 15 del principio de los Ejercicios, dice así: "Dado que fuera de los Ejercicios lícita y meritoriamente podamos mover á todas personas, que probahiliter tengan subyecto, para elegir continencia, virginidad, religión y toda manera de perfectión evangélica; tamen en los tales Ejercicios espirituales, más conveniente y mucho mejor es, buscando la divina voluntad, que el mismo Criador y Señor se comunique á la su ánima devota abrasándola en tu amor y alabanza, y disponíendola por la vía que mejor podrá servirle adelante".
} 


\section{San Juan de Ávila y la llegada de los Jesuitas a CóRdoba, Andalucía}

\section{Huéspedes en la casa del Deán}

Cuando Villanueva y Alonso López partieron para Córdoba, la marquesa les dio cartas de recomendación para su pariente D. Juan de Córdoba, a quien pedía que mientras ella les preparaba la Casa del Agua, los hospedara él en la suya $^{150}$. No recibió con agrado la recomendación de la marquesa, pues tenía prejuicios contra la Compañía, incluso se había opuesto, como capitular, a la llegada de los jesuitas ${ }^{151}$ con la frase "esse Teatinum esse desatino"152. A pesar de ello, mandó al criado de la marquesa a buscarlos al hospital donde se habían instalado en un principio, los recibió y los alojó en su casa, con la intención, más bien, de someterlos a una estrecha vigilancia que llegó al extremo de levantarse a media noche para espiarlos por el ojo de la cerradura de la puerta.

Empezaba a cambiar su opinión al verlos siempre ocupados en leer y rezar, pero le llegaron noticias de un calumniador que decía que sus huéspedes salían de noche. Después supo que era para confesar a un moribundo ${ }^{153}$. Desde entonces, con estos ejemplos y la conversación con el P. Villanueva ${ }^{154}$, cambió su actitud y se hizo fervoroso defensor y protector de la Compañía toda su vida ${ }^{155}$.

El P. Villanueva fue introducido en el Ayuntamiento el 13 de octubre con cartas de recomendación de la marquesa, y explicó a los regidores algo sobre la Compañía y su intención de fundar en Córdoba. La propuesta fue bien recibida por la Ciudad, que se mostró dispuesta a contribuir económicamente ${ }^{156}$.

Borja y Bustamante, por su parte, pudieron salir de Évora el 10 de octubre y llegar a Córdoba el 18, yéndose a alojar en un mesón en las afueras de la ciudad. Cuando Villanueva supo que estaban allí fue a buscarlos y los llevó a la casa de D. Juan a la puesta del sol, y de ahí partieron al día siguiente a Montilla para cumplimentar a la marquesa ${ }^{157}$.

\footnotetext{
${ }^{150}$ ARSI, Baet 22, 39-51: «Sumario del origen, fundación y progreso del colegio de la Compañía de Jesús de Córdoba»; Roa y Santibáñez.

${ }^{151}$ Bartolomé Bustamante a Ignacio de Loyola, Córdoba 20.10.1553, EppMixtae III, 551.

${ }^{152}$ Pedro Navarro a Ignacio de Loyola, 01.03.1554, LitQuad IV 697.

${ }^{153}$ Roa, «Historia», Libro I, cap. 2.

${ }^{154}$ Pedro Navarro a Ignacio de Loyola, 01.03.1554, LitQuad IV 697; Bustamante a Ignacio de Loyola, 31.10.1553, EppMixtae III, 574.

${ }^{155}$ Por comisión de Manuel López, a Ignacio de Loyola, Alcalá, 31.12.1553, LitQuad, II, 500.

${ }^{156}$ Ribadeneira, «Historia de la Compañía de Jesús en sus provincias de España», libro 1, cap. 23 (ARSI, Hisp 94).

${ }^{157}$ Bartolomé Bustamante a Ignacio de Loyola, Córdoba 20.10.1553, EppMixtae III, 551.
} 


\section{Wenceslao Soto Artuñedo, S.J.}

\subsection{Segundo proyecto: el Deán D. Juan de Córdoba}

Ofrecimiento del deán

D. Juan recibió muy bien a Borja, y con su trato se consolidó el cambio de actitud que había experimentado con Villanueva, de manera que, una vez que Borja partió para Montilla, prometió hacer la donación de sus casas principales, donde vivía, para el colegio. Él mismo, en una carta a san Ignacio, una vez que ya había muerto pero cuya noticia no era aún conocida en Córdoba, le cuenta cómo cambió sus iniciales reticencias a la Compañía, por un gran fervor ${ }^{158}$.

Este ofrecimiento suponía una gran mutación al proyecto ya aprobado por el Ayuntamiento, por lo que el veinticuatro Juan Martín de Caicedo informaba en el cabildo de 23 de octubre que el deán pensaba dejar sus casas principales y otras anexas a ellas y ajuar de capilla para la Compañía de Jesús. Aunque el Ayuntamiento estaba en conversaciones con la marquesa y D. Antonio, creía que era mejor la oferta del deán, por lo que sugiere que se confirme esta disposición, por ser "tan aventajada la merced que el señor don Juan agora hace", y pide que se vaya a visitarlo para agradecérselo y a ofrecerle la ayuda municipal en lo que fuera menester ${ }^{159}$.

El mismo Caicedo se desplazó a Montilla para informar de la buena disposición del Ayuntamiento y de D. Juan de Córdoba, y a pedirle a la marquesa que siguiera apoyando la fundación del colegio de Córdoba ${ }^{160}$, de cuya visita se informa en el cabildo de 25 de octubre. Por su parte, los diputados para visitar a D. Juan informaron que éste había ratificado su propósito de entregar a la Compañía sus casas principales y otras cosas, para lo que dio poder al maestro Juan de Ávila, según "que con él lo había tratado". Entregaba la casa (que valía más de 8.000 ducados "pero no se haría ahora con 12.000"), ornamentos y plata por valor de más de 3.000 ducados y se obligaba a hacer la capilla con su reja y retablo, dotando su fábrica con más de 20.000 maravedís. En el poder a Juan de Ávila autorizaba a que concertase con la Ciudad lo que ésta debía aportar. Ávila advirtió que las casas de D. Juan estaban cargadas con un rédito anual, ya que debía 600.000 maravedís de la compra del solar, y decidió que la Ciudad debía redimir esa carga, para que las casas pasasen libres a la Compañía, compromiso que adquirió el Ayuntamiento, para cuanto D. Juan hiciese la donación ${ }^{161}$, y D. Juan se obligó a hacer la donación

\footnotetext{
${ }^{158}$ Juan de Córdoba a Ignacio de Loyola, Córdoba 10.09.1556, EppMixtae, V, 439.

${ }^{159}$ Cabildo 23 octubre 1553, Sala, Obras completas (1970), 160.

${ }^{160}$ Santibáñez, «Historia», parte $1^{\text {a }}$, libro $1^{\circ}$, cap., 18.

161 Archivo Municipal de Córdoba [AMC], 25 octubre 1553, Sala, Obras completas (1970): 160-161.
} 


\section{SAn Juan de Ávila y la llegada de los Jesuitas a CóRdoba, Andalucía}

cuando decidiera el maestro Juan de Ávila "que es el que ha mucho trabajo en este negocio". El 31 de octubre escribía Bustamante a Ignacio explicando esa situación ${ }^{162}$.

Borja en el Ayuntamiento

Dada la nueva situación, Borja volvió de Montilla y se personó junto con D. Antonio en el cabildo de 3 de noviembre, repitiendo el ofrecimiento que había hecho ya Villanueva. A su salida determinó el Ayuntamiento que el alcalde mayor y los diputados del colegio, fuesen a devolver la visita "al duque de Gandía e don Antonyo de Córdova" y agradecerle su venida para fundar el colegio y hacerles presente el compromiso de la ciudad ${ }^{163}$.

Se nombraron diputados para hacer las escuelas, con 900.000 maravedíes que el ayuntamiento tenía disponibles. Además, había pedido licencia al rey para dar una renta anual al colegio (con la pretensión de que fuese universidad) de 600.000 maravedís. Esto, junto con los beneficios de D. Antonio sumaba 2.500 ducados de renta ${ }^{164}$. La marquesa de Priego había dado 5.000 maravedíes de renta, pan, aceite y otras cosas ${ }^{165}$.

En la ciudad fue muy bien acogida la llegada de la Compañía y muchos particulares ofrecían limosnas para acrecentar la renta del colegio ${ }^{166}$.

\section{Comienzo de las clases en una sede provisional}

\subsection{Primera sede del colegio}

Borja informó a San Ignacio de su gestión en Córdoba, cómo D. Juan de Córdoba decidió donar sus casas, y, mientras las habilitaba, prestaba otra casa del cabildo que tenía en usufructo vitalicio ${ }^{167}$. Es probable que el donativo de 1.000 ducados que la marquesa tenía previsto gastar en acomodar las Casas

\footnotetext{
${ }^{162}$ Bartolomé Bustamante a Ignacio de Loyola, Córdoba, 31.10.1553, EppMixtae III, 574-575; Pedro Navarro a Ignacio, Córdoba 1 marzo 1554, LitQuadr, IV, 698.

${ }^{163}$ AMC, Cabildo 3 de noviembre 1553. A este mismo acuerdo se refiere Martín de Roa: "Con esta respuesta señaló el Ayuntamiento por diputados de la fábrica y obra pública a don Joan de Cárdenas y a don Diego Fdez de Córdova. Con otros tres cavalleros veintiquatros y dos jurados a quien dieron su poder y vezes para gastar y distribuir en el edifiçio de las escuelas y collegio como con obra que legítimamente perteneçe al bien público, todos los maravedisses que fuessen neçesarios del encabeçamientio general, sin alguna limitaçión." (Roa, "Historia", cap. 3)

${ }^{164}$ Antonio Gou a Ignacio de Loyola, Valladolid 13.10.1553, EppMixtae III, 527-528.

${ }^{165}$ Manuel López a Ignacio de Loyola, Alcalá 07.08.1553, LitQuad., IV, 671-672.

${ }^{166}$ Bartolomé Bustamante a Ignacio de Loyola, Córdoba 31.10.1553, EppMixtae III, 575.

${ }^{167}$ Borja a Ignacio de Loyola, Córdoba, 25.12.1553, Borgia, III, 156-157.
} 


\section{Wenceslao Soto ArtuÑedo, S.J.}

del Agua los invirtiese en preparar esta casa del deán "por comprar las cámaras, y schuelas, y servimento y veste de los hermanos y Padres"168.

Cuando Villanueva supo la intención del deán de donar sus casas, pidió al comisario Borja un número suficiente de sujetos para incoar el colegio y establecer los estudios de letras humanas y retórica y, en el futuro, las facultades superiores ${ }^{169}$. Borja escribió al colegio de Alcalá indicando los sujetos que habían de partir inmediatamente para Córdoba junto con otro de Medina del Campo, que, siguiendo sus órdenes, pasarían por Montilla para cumplimentar a la marquesa, donde un grupo de ellos permaneció casi un mes en una casa preparada por $\mathrm{D}^{\mathrm{a}}$. Catalina, mientras se disponía la de Córdoba ${ }^{170}$.

En las casas del deán esperaban Francisco de Villanueva y Alonso López. A ellos se sumó el primer grupo el 23 de noviembre de 1553, los PP. Juan de la Plaza $^{171}$ y Miguel Ramírez con los hermanos Diego Cavallar, Diego Martínez y Hernando de Hayas. Se les unieron después Francisco de Borja, D. Antonio de Córdoba, Bartolomé Bustamante, Pedro Navarro, P. Benedicto, y el H. Antonio Ramírez. A los pocos días se incorporaron Juan de Jaén y los HH. Marcelo y Juan de Roca.

\subsection{Inauguración del colegio y de las clases}

El colegio se inauguró el 25 de noviembre de 1553, día de Santa Catalina. Ese día el deán quiso que predicase Francisco de Borja en la iglesia parroquial de Santo Domingo, cerca de su casa, y, después, honró a todos con una comida y sobremesa ${ }^{172}$.

A los pocos días, el 11 de diciembre ${ }^{173}$, comenzaban las escuelas con cuatro clases de gramática y una de retórica, después de preparar las cátedras para los maestros y asientos para los discípulos. "En tan pocos días nunca la Compañía ha sido recibida en parte alguna de España con tanta voluntad y grata aceptación como aquî’” ${ }^{174}$. Para esta ocasión acudieron el obispo, el deán, el

\footnotetext{
${ }^{168}$ Jerónimo Nadal a Ignacio de Loyola, Valladolid 15.03.1554, Natalis I, 221.

${ }^{169}$ Chron III, 350-352 nn. 774-775.

${ }^{170}$ Borja a Ignacio de Loyola, Córdoba, 25.12.1553, Borgia, III, 156-157; Santibáñez, "Historia", parte $1^{\mathrm{a}}$, libro $1^{\circ}$, cap. 20.

${ }^{171}$ En noviembre partieron de Alcalá, para Córdoba, el doctor P. Juan de Plaza, recién entrado en la Compañía, con tres hermanos, uno para servir y dos para proseguir sus estudios de gramática, cf. Antonio Gou a Ignacio de Loyola, Valladolid 27.11.1553, EppMixtae III, 631; Por comisión de Manuel López, a Ignacio de Loyola, Alcalá, 31.12.1553, LitQuad, II, 498-505.

${ }_{172}$ Borja a Ignacio de Loyola, Córdoba, 25.12.1553, Borgia, III, 156-157.

${ }^{173}$ Francisco de Borja a Ignacio de Loyola, Córdoba 25.12.1553, Borgia III, 157-158. Según Roa, el 3 de diciembre.

${ }^{174}$ Francisco de Borja a Ignacio de Loyola, Córdoba 25.12.1553, Borgia III, 157-158.
} 


\section{SAn Juan de Ávila y la llegada de los Jesuitas a CóRdoba, Andalucía}

inquisidor y otros caballeros, tuvo una oración principal el maestro Benedicto Catalán, en alabanza de las ciencias y, por la tarde disertó el H. Marcelo, maestro de Retórica ${ }^{175}$.

Al día siguiente, Juan de Jaén, que había sido profesor de Griego en Alcalá, examinó a los alumnos y los distribuyó por niveles "en çinco generales donde se les avía de leer la grammática y retórica" ${ }^{176}$. Miguel Ramírez se encargó de la clase de medianos y al $\mathrm{H}$. Roca se le encomendó la de mayores ${ }^{177}$.

Poco después llegó el P. Jerónimo Nadal, comisario de Ignacio de Loyola, con Miguel de Torres (que había sido rector de Salamanca), el 23 de diciembre, después de pasar por Montilla. Nadal procuró que el sistema de estudios y el modo de enseñar los jesuitas las artes liberales se ajustasen a lo que se practicaba en el colegio Romano, pues habían empezado a enseñar "a su modo"178.

Según señala Polanco, en alabanza del colegio cordobés, éste fue el primero en España donde, desde su mismo comienzo y sin interrupción, se instituyeron las escuelas para no jesuitas y se prosiguieron, pues en los demás colegios no se habían encargado de tales escuelas inmediatamente: No obstante, el primer colegio donde los jesuitas enseñaron también a no jesuitas fue en el colegio y universidad de Gandía, pero no perseveró con este empeño, ya que se dejaron las escuelas de gramática con sus rentas, a petición de las autoridades locales, aunque prosiguieron los estudios de artes y teología ${ }^{179}$.

Como hemos visto, el colegio pudo crearse gracias al impulso decisivo de D. Juan, pero también al apoyo del Ayuntamiento, D. Antonio y la marquesa. Por ello, antes de nombrar a D. Juan fundador del colegio, san Ignacio quiso pedir el parecer de Borja, como más informado ${ }^{180}$. San Ignacio le escribió pasados unos meses, agradeciendo toda su colaboración ${ }^{181}$.

Coincidiendo con la visita de P. Nadal, D. Juan de Córdoba ofreció oficialmente sus casas con escritura pública, pero todo estuvo a punto de arruinarse cuando Nadal supo que el benefactor tenía una amante en una de sus casas. Nadie había conseguido sacarlo de esta situación, y por eso había sido eliminado de las listas para promoción en cargos eclesiásticos. Una vez que lo descubrió el P. Nadal, reunió a todos los del colegio en una sala y les dio una plática para hacerles reflexionar en el sentido de que la Compañía debía buscar almas para Dios y no haciendas a cualquier precio, instándolos a la oración

\footnotetext{
${ }^{175}$ Roa, "Historia", lib. 1, cap. 3.

${ }^{176}$ Ibidem.

177 BUG, BHR, Caja A-049 (8).

178 Santibáñez, "Historia", parte $1^{\mathrm{a}}$, libro $1^{\circ}$, cap. 21.

${ }^{179}$ Chron IV, no 978, 458, cf. Medina, "El proceso fundacional".

${ }^{180}$ Ignacio (por comisión a Polanco) a Borja, 08.03.1554, EppIgn. VI, 438.

${ }^{181}$ Ignacio de Loyola a D. Juan de Córdoba, 17.09.1554, EppIgn. VII, 529.
} 


\section{Wenceslao Soto ArtuÑedo, S.J.}

para pedir la conversión de D. Juan. Puso a la comunidad en la disyuntiva de que o debían renunciar a la casa y hacienda de D. Juan o ganar su alma para Dios. A los pocos días el deán hizo sacar a su manceba públicamente de su casa. Así se disolvió el rumor de que la Compañía disimulaba los vicios de D. Juan para sacarle dinero ${ }^{182}$.

\section{Colegio-Universidad}

En la escritura de donación ${ }^{183}$, se recogía el compromiso del Ayuntamiento de gestionar la erección de una universidad:

los muy ilustres señores concejo regimiento de la dicha ciudad de Córdoba [...] tienen a cuidado de suplicar a Su Santidad y a Su Majestad o al Príncipe nuestro señor, sean servidos de erigir en esta ciudad universidad de estudios generales en todas ciencias y facultades, la cual sea de la dicha Compañía de Jesús, según Su Santidad y Majestad o Alteza lo concediere.

Llegado el momento, D. Juan promete unirse a la petición.

También se definen algunas características de esa futura universidad. Competía a la Compañía el nombramiento de profesores para todas las facultades, jesuitas o no, sin otra intervención, pues confiaban en que la Compañía pondría lectores adecuados. A todos los podía remover cuando le pareciere, encomendando a sus conciencias todas las lecciones y los profesores, excepto en las facultades de Cánones, Leyes y Medicina, si bien para todas las facultades era preceptivo disponer de la aprobación de la Compañía.

Para la provisión de profesores de las facultades de Cánones, Leyes y Medicina, quedando vacante una plaza, se debía publicar en las universidades que se creyera conveniente para que vinieran a opositar. En la oposición debían hallarse presentes al menos cinco letrados, doctores o licenciados en esa facultad, elegidos por la Compañía. Les tomarían los votos en presencia del deán, una dignidad y un canónigo elegidos por el cabildo, y en presencia del corregidor, un veinticuatro y un jurado designado por el cabildo secular. Se le daría la cátedra a quien obtuviera más votos. Si estos letrados hubieran de venir de fuera por no haberlos en Córdoba, se les daría el estipendio que se considerase conveniente con cargo a la cátedra, y si no llegase esta cantidad,

${ }^{182}$ Chron IV, nn 971-972; Antonio Astrain, Historia de la Compañía de Jesús en la Asistencia de España, 7 vol., (Madrfid: Razón y Fe, 1902-1925), I, 417.

${ }^{183}$ Documento de donación del colegio de Córdoba, ante Alonso de Toledo, 24.01.1554, ARSI, FG 1404/4, 3; AHPC, Protocolos, leg. 16.802-P. Escritura de donación y fundación dada en Córdoba, el 24 de enero de 1554, ante Alonso de Toledo, escribano público de Córdoba, Fols. 41r-54v., en Díaz Rodríguez, «El Colegio de Santa Catalina», 93-103. 


\section{SAn Juan de Ávila y la llegada de los Jesuitas a CóRdoba, Andalucía}

se les descontaría de lo que habrían de percibir por la cátedra. Ninguna provisión para estas cátedras debería ser por más de cuatro años.

A petición de la misma Compañía se fija una cláusula en los siguientes términos: así como los jesuitas podrían quitar y poner libremente a cualquier profesor, no pueden hacerlo con los de estas cátedras, una vez elegidos, salvo con la opinión favorable del deán, una dignidad y un canónigo (elegidos por el cabildo eclesiástico), del corregidor, de un veinticuatro y de un jurado (elegidos por el cabildo civil). La propuesta debería tener al menos tres votos, además del voto del rector del colegio.

A petición de los jesuitas también se añadió que ellos no intervendrían en el cobro de las rentas de esas tres cátedras y su pago, por lo que el ayuntamiento debía nombrar un diputado para que lo hiciera.

Ninguna persona distinta a las nombradas por la Compañía podría dar clase en la universidad, sin permiso expreso del rector, que libremente podría retirar un permiso concedido. Si alguna otra persona quisiera instituir una nueva cátedra, en cánones, leyes o medicina, la Compañía estaría obligada a admitir al profesor designado por el donante, si era adecuado, mientras viviera el instituidor. En ese caso, el rector procuraría que no perjudicase a los que ya hubiera, debiendo el nuevo profesor prometer obediencia al rector. Al morir el instituidor de esta nueva cátedra, el profesor se nombraría por el procedimiento habitual.

La Compañía se ofreció a conceder gratis los grados y a dar las clases y tener otros ministerios, también gratis, por lo que respectaba a la Compañía, pues habría de pagarse su parte a los no jesuitas que tuvieran derecho a ello. La Compañía no quedaba obligada hasta que el colegio y las cátedras estuvieran suficientemente dotadas, según tiene establecido la Compañía para este tipo de instituciones, y la obligación sería como la Compañía quiera obligarse. Lo que hicieran entre tanto, es de modo voluntario. Nadal comentaba:

El negocio y buena voluntad de todos los de la ciudad y del P. Mo Ávila y el exemplo que fue grande en Spaña, y fruto que se spera en el Señor, hizieron que nos ofreciéramos a tanto, tamen sin obligación alguna, como V. P. verá ${ }^{184}$.

San Ignacio asumió este compromiso: "In Cordoua de Spagna si fece, non solamente collegio, ma etiam uniuersità della Compagnia" 185 . Un mes después de la fundación, Borja había informado a Ignacio de sus conversaciones con el Licenciado del Pozo, agente de la Iglesia cordobesa en Roma, para que obtuviese la facultad apostólica de erigir Universidad en Córdoba, cuya superintendencia estuviera a cargo del colegio de la Compañía, pues lo deseaba

\footnotetext{
${ }^{184}$ Nadal a Ignacio, Córdoba 15 de marzo 1554, Natalis I, 221-223.

${ }^{185}$ Ignacio a los rectores de colegios, por comisión, Roma, 01.05.1554, EppIgn VI, 665.
} 


\section{Wenceslao Soto Artuñedo, S.J.}

D. Juan, quien había pedido a Borja que intercediera con Ignacio para que favoreciera la suplicación ${ }^{186}$.

Se iniciaron las gestiones con Julio III que había confirmado a la Compañía en 1550, a quien escribió D. Juan en 1555, pero la muerte del pontífice interrumpió el proceso. Por ello, el P. Bustamante se quejaba en 1558 de que los estudiantes de Artes de Córdoba tuvieran que ir a otras universidades a conseguir el grado y D. Juan de Córdoba había escrito varias veces a san Ignacio sobre esto, para que se procurase una bula que convirtiera al colegio de Córdoba en Universidad, donde se pudiesen dar grados en todas las facultades ${ }^{187}$.

Los teólogos y filósofos hacían conclusiones mensuales, con la participación de los dominicos, a quienes se correspondía asistiendo a las suyas. Entre los alumnos a veces había religiosos, como los 4 religiosos del convento cordobés franciscano de la tercera Orden, de la Madre de Dios, tres de ellos gramáticos, y el otro teólogo, que había en 1561. Pero no llegaba la universidad, por lo que en 1561 los artistas tuvieron que ir a Sevilla a hacerse bachilleres; en este año lo consiguieron 22 estudiantes ${ }^{188}$.

Pasados unos años retomó el tema la V Congregación Provincial, presidida por el P. Pedro Bernal, el 15 de octubre de 1575, para urgirle al P. General Everardo Mercurián, la consecución de este objetivo. Respondió el General que la Compañía no debía tomar la iniciativa, pues correspondía a la ciudad de Córdoba, ya que esta era la principal interesada, y no se debía cargar la Compañía unilateralmente con la función de dotar de profesores a esta nueva institución. Por ello, pensaba que esta gestión se debía remitir a la Ciudad ${ }^{189}$.

El 25 de mayo de 1576 se personó en el ayuntamiento el rector, P. Francisco Gómez y expuso lo importante que era que hubiera universidad en el colegio para poder graduar de bachiller y otros grados a los estudiantes, con lo que se ahorrarían los gastos para ir a graduarse fuera. La propuesta fue bien acogida, siendo el principal valedor el corregidor Garci Suárez de Carvajal y se nombró una comisión para recabar el apoyo del obispo y del cabildo catedralicio, de cuya gestión se informó en la sesión de 13 de junio: El obispo fray Bernardo de Fresneda lo aceptaba en un primer momento, "con que no tengan juridiçion por ninguna via" mientras que el cabildo eclesiástico decidió aplazar su respuesta hasta conocer la del obispo que se mostró contrario al proyecto en una segunda oportunidad, el día 15. Ese mismo día, el corregidor sometió a debate la iniciativa de otorgar grados en las facultades de teología,

\footnotetext{
${ }^{186}$ Borja a Ignacio. Córdoba 25 diciembre 1553. Borgia III, 159.

${ }^{187}$ Bartolomé Bustamante a Juan de Polanco, Toledo 29.11.1558, Laínez, III, 705.

${ }^{188}$ Antonio de Fonseca, Córdoba 29.12.1561, LitQuad. VII, 600-606.

${ }^{189}$ Santibáñez, "Historia", parte $1^{\text {a }}$, libro $1^{\text {o }}$, cap. 21.
} 


\section{SAn Juan de Ávila y la llegada de los Jesuitas a CóRdoba, Andalucía}

derecho y medicina, exponiendo las ventajas que eso traería y solicitó pedir permiso real para que el cabildo escribiese al papa en apoyo de la universidad "y con el dicho ofrecimiento que no a de adquirirse jurisdiçion alguna para siempre en tiempo alguno". Los esfuerzos del corregidor resultaron infructuosos finalmente, por la oposición del obispo, que determinó la falta de apoyo del cabildo eclesiástico y el poco entusiasmo en el cabildo civil.

La negativa del obispo obedece a que en 1574 había obtenido permiso de Gregorio XIII para disponer de 40.000 ducados para erigir una universidad en el convento franciscano de Santo Domingo de la Calzada, donde mandó ser enterrado ${ }^{190}$.

El general jesuita dio instrucciones al visitador en 1578 sobre este tema: Se ha intentado convertir el colegio de Córdoba en universidad, por ser el principal seminario de esa provincia, pero eso no puede tener efecto sin la voluntad del rey. Ahora, que el duque de Sessa iba a residir en la corte, se podría intentar conseguir, pues el duque de Sessa, como protector del colegio de Córdoba, tenía voluntad de conseguir este objetivo. El seminario de Teología de esa provincia estaba en este colegio, y, por tanto, aquí venían a estudiar los mejores de cada colegio, por lo que también era de interés para la Compañía la consecución de la universidad ${ }^{191}$.

Otra iniciativa se pone en marcha en 1592, siendo rector el P. Francisco Duarte, cuando pidió el apoyo del cabildo, pero, de nuevo, quedó baldía la propuesta, no se llegó hasta el término que se esperaba, y, finalmente, se abandonó el proyecto ${ }^{192}$.

Igualmente quedó frustrado el proyecto de una cátedra de medicina, a pesar de que se cumplían las condiciones impuestas por el doctor Diego Fernández de Inquinira médico afincado en Córdoba, que dejó la dotación para ello en su testamento de $1558^{193}$.

No obstante, los pontífices concedieron a los jesuitas la facultad de otorgar grados; primero, por un privilegio pontificio de Julio III en 1552 y confirmado y ampliado por Pio IV, en 1561, que fue usado en Córdoba y Sevilla ${ }^{194}$. Poste-

\footnotetext{
${ }^{190}$ AMC, Actas Capitulares, 87, fol. 161, 179r, 25.05 .1576 y 13.06.1576, citadas por Juan Aranda Doncel, Cosme Muñoz (1573-1636). Una vida entregada a la causa de Dios (Córdoba: Congregación de las Hijas del Patrocinio de María, 2012), 152-154; Juan Aranda Doncel, «Dos proyectos educativos, en la Córdoba del siglo XVI: la creación de universidad y la dotación de una cátedra de medicina en el colegio de los jesuitas», en Politica, Religión e Inquisición en la España Moderna. Homenaje a Joaquín Pérez Villanueva, ed. por P. Fernández Albadalejo y otros (Madrid: Universidad Autónoma, 1996), 59-83, 70-75.

${ }^{191}$ Instrucciones para el visitador de Andalucía, 4.01.1578, ARSI, Hisp, 89, 27.

${ }^{192}$ BUG, BHR, Caja A-049 (8); cf. Aranda, Cosme Muñoz..., 154; Aranda, «Dos proyectos educativos», 59-83, 75-80.

${ }^{193}$ Aranda Doncel, «Dos proyectos educativos», 80-83.

${ }^{194}$ Medina, «El proceso fundacional».
} 


\section{Wenceslao Soto Artuñedo, S.J.}

riormente, Gregorio XIII concedió la facultad de conferir grados de bachiller y licenciado por una bula de 7 de mayo de $1578^{195}$.

Habrá que esperar que pasen algunos siglos para que, finalmente, aquel sueño de una universidad jesuita para Córdoba se hiciera realidad. Así ocurrió inicialmente con la Escuela Técnica de Empresarios Agrícolas (ETEA) en 1968, y más formalmente con la Universidad Loyola como heredera de ETEA en 2010, que, precisamente ha inaugurado oficialmente el 20 de noviembre de 2019 un nuevo campus en Dos Hermanas (Sevilla).

\section{Fuentes y Bibliografía}

Archivos

ADM: Archivo Ducal Medinaceli, Sevilla, Priego.

AHPC: Archivo Histórico Provincial de Córdoba, Protocolos notariales.

AMC: Archivo Municipal Córdoba, Actas Capitulares.

ARSI: Achivum Romanum Societatis Iesu, Baetica [Baet], Fondo Gesuitico[FG], Hispania [Hisp].

BUG: Biblioteca Universidad de Granada, Biblioteca Hospital Real, Caja MS-1-008 (8).

Caja A 49: ROA, Martín, «Historia de la Compañía de Jesús en la Provincia de Andalucía».

Caja B-50: SANTIBÁÑEZ, Juan de, «Historia de la Provincia de Andalucía de la Compañía de Jesús».

\section{Fuentes editadas}

MHSI: Monumenta Historica Societatis Iesu.

Borgia: Sanctus Franciscus Borgia, quartus Gandiae dux et Societatis Iesu praepositus generalis tertius, 5 vol Madrid, 1894-1911, (nn. 2, 23, 35, 38, 41).

Chron: Vita Ignatii Loiolae et rerum societatis Iesu, Historia. Auctore Joanne Alphonsus de Polanco, 6 vol, Madrid 1894-1898, (nn.1, 3, 5, 7, 9, 11).

EppIgn: Sancti Ignacii Loyola Societatis Iesu fundatoris epistolae et instructiones, 12 vol. Madrid 1903-1911, reimpresión 1964-1968 (nn. 22, 26, 28, 29, 31, 33, 34, 36, 37, 38, 40, 42).

EppMixtae: Epistolae Mixtae ex variis europae locis ab anno 1537 ad 1556 scriptae, 5 vol. Madrid, 1898-1901 (nn. 12, 14, 17, 18, 20.).

Lainii: Lainii Monumenta. Epistolae et Acta Patris Jacobi Lainii secundi praepositi generalis Societatis Iesu, 8 vol. Madrid 1912-1917 (nn. 44, 45, $47,49,50,51,53,55)$.

${ }^{195}$ Cf. Aranda Cosme Muñoz: 154. 
San Juan de Ávila y la llegada de los Jesuitas a Córdoba, Andalucía

LittQuad: Litterae Quadrimestres ex universis praeter Indiam et Brasiliam locis, in quibus aliqui de Societate Iesu versabantur. 7 vol., Madrid 18941932 (nn. 4, 6, 8, 10, 59, 61, 62).

Natalis: Epistolae P. Hieronymi Nadal Societatis Iesus ab anno 1546 ad 1577 (et alia scripta), 5 vol Madrid-Roma, 1898-1962, (nn. 13, 15, 21, 27, 90).

\section{Bibliografía}

Aranda Doncel, Juan. «Instituciones educativas andaluzas en el Antiguo Régimen: las constituciones del Colegio de la Asunción de Córdoba durante el siglo XVI». Boletín de la Real Academia de Córdoba de Ciencias, Bellas Artes y Nobles Letras LVIII/112 (1987): 5-22.

Aranda Doncel, Juan «Dos proyectos educativos, en la Córdoba del siglo XVI: la creación de universidad y la dotación de una cátedra de medicina en el colegio de los jesuitas". En Política, Religión e Inquisición en la España Moderna. Homenaje a Joaquín Pérez Villanueva. Editado por P. Fernández Albadalejo y otros. Madrid: Universidad Autónoma, 1996, 59-83, 70-75.

Aranda Doncel, Juan. Cosme Muñoz (1573-1636). Una vida entregada a la causa de Dios. Córdoba: Congregación de las Hijas del Patrocinio de María, 2012.

Aranda Doncel, Juan, «San Juan de Ávila y el clero diocesano cordobés durante los siglos XVI al XVIII». En San Juan de Ávila, doctor de la Iglesia. Actas del Congreso Internacional. Editado por Aranda Doncel, Juan y Antonio Llamas Vela. Córdoba: Diputación, 2013, 157-201.

Aranda Doncel, Juan y Luis Segado Gómez. Villafranca de Córdoba. Un señorío andaluz durante la Edad Moderna (1549-1808). Córdoba 1992.

Astrain, Antonio. Historia de la Compañía de Jesús en la Asistencia de España, 7 vol. Madrid: Razón y Fe, 1902-1925.

Bellido Vela, Elena. El desaparecido convento franciscano de San Lorenzo de Montilla. Definición geométrica y representación gráfica. Tesis doctoral. Universidad de Córdoba, 2019. http://geneall.net/H/per_page. php?id=62049

Burrieza Sánchez, Javier. «La Compañía de Jesús que conoció Juan de Ávila», en Entre todos, Juan de Ávila, editado por M. ${ }^{\text {a }}$ E. González Rodríguez. Madrid: BAC, 2011, 51-58.

Delgado, Mariano, «"“...todos los males y perturbaciones de la Compañía han venido de ellos". Reflexiones acerca del giro anti-converso en la Compañía de Jesús», en Diego Laínez (1512-1565) and his Generalate. Jesuit with Jewish Roots, Close Confidant of Ignatius of Loyola, Preeminent Theologian of the Council of Trent. Editado por Paul Oberholzer. Roma: Bibliotheca Instituti Historici Societatis Iesu, 2015, 192-213. 


\section{Wenceslao Soto Artuñedo, S.J.}

DHCJ: O’Neill, Charles E. y Domínguez, Joaquín M. ${ }^{a}$ (Dirs.), Diccionario Histórico de la Compañía de Jesús, 4 vol. Roma / Madrid: Institutum Historicum S. I. / Universidad Pontificia de Comillas, 2001.

Díaz Risco, Juan. «Francisco de Villanueva, primer jesuita alumno de la Universidad de Alcalá». Anales Complutenses XXV1l (2015): 163-191.

Díaz Rodríguez, Antonio José. «El Colegio de Santa Catalina de Córdoba: notas sobre su documento fundacional». Ámbitos. Revista de estudios de Ciencias Sociales y Humanidades 19 (2008): 93-103.

Díaz Rodríguez, Antonio José. «Las casas del deán don Juan de Córdoba: lujo y clientela en torno a un capitular del renacimiento». Hispania Sacra LXI (2009): 77-104.

Díaz Rodríguez, Antonio José. «Córdoba, Juan de». En Real Academia de la Historia, Diccionario Biográfico Español, vol. XIV, Madrid, 2010.

Fernández de Béthencourt, F. Historia genealógica y heráldica de la monarquía española. Sevilla: Casa Real y grandes de España, 2003, Tomo VII.

Fernández De Córdoba, F., Historia y descripción de la Casa de Córdoba. Córdoba: Real Academia de Córdoba, 1954.

García Hernán, Enrique. «Ignacio de Loyola y Juan de Ávila en 1538». En Entre todos, Juan de Ávila, editado por $\mathrm{M}^{\mathrm{a}}$. E. González Rodríguez. Madrid: BAC, 2011, 129-132.

González Chávez, Alberto José. Juan de Ávila, Messor eram. Vida y obra, ministerio y actualidad del santo patrono del clero secular español. Aranjuez: Xerión, 2019.

Granada, Fray Luis de. Vida del Padre Maestro Juan de Ávila y las partes que ha de tener un predicador evangélico. Madrid, 1588. Madrid: Edibesa 2000.

Jiménez Fernández, Antonio. El sepulcro y el cuerpo de San Juan de Ávila. Montilla 1986.

López Arandia, María Amparo, «¿Caminos encontrados? Juan de Ávila y la Compañía de Jesús». En El maestro Juan de Ávila (1500-1569). Un exponente del humanismo reformista. Editado por M. ${ }^{a}$ Dolores Rincón González y Raúl Manchón Gómez. Salamanca / Jaén: Universidad Pontificia de Salamanca / Universidad de Jaén, 2014, 567-591.

López Pego, Carlos. «El inusitado y extraño fenómeno vocacional de los estudiantes de la Universidad de Alcalá hacia la Compañía de Jesús (15451634)». Hispania Sacra LXI (2009): 159-190.

Luque Ruiz, E. «La Real Colegiata de San Hipólito: relicario de historia y de fe». Boletín de la Real Academia de Córdoba 106 (1984): 191-207.

Martínez Rojas, Francisco Juan. «La formación cultural del clero giennense en el período pretridentino y la labor renovadora de san Juan de Ávila y la Universidad de Baeza». XX Siglos 14/52 (2003): 65-73. 


\section{San Juan de Ávila y la llegada de los Jesuitas a CóRdoba, Andalucía}

Medina, Francisco de Borja, «Íñigo López de Loyola: Probable estancia en Sevilla (1508-1511) y su reflejo en los Ejercicios». Archivum Historicum Societatis Iesu 63 (1994): 3-75.

Medina, Francisco de Borja. «El proceso fundacional de la provincia de Andalucía (1545-1554)». en Los jesuitas en Andalucía. Estudios conmemorativos del 450 aniversario de la fundación de la Provincia. Editado por Wenceslao Soto Artuñedo. Granada: Editorial Universidad de Granada / Facultad de Teología, 2007: 49-162.

Molina Recio, Raúl, «Formación y evolución del marquesado de Priego en la Edad Moderna. Puente Genil y la casa de Córdoba». En Puente Genil. Pasado y presente. I Congreso de Historia, Puente Genil. Coordinado por E. Soria Mesa. Córdoba: Universidad de Córdoba / Ayuntamiento de Puente Genil, 2002, 375-389.

Molina Recio, Raúl. La nobleza en la España Moderna: los Fernández de Córdoba. Familia, riqueza, poder y cultura. Tesis Doctoral Universidad de Córdoba 2004. https://helvia.uco.es/xmlui/handle/10396/6269

Molina Recio, Raúl. «Nobleza y poder señorial. Los señoríos andaluces de los Fernández de Córdoba en la Edad Moderna. Territorio, población y economía». En Los señoríos en la Andalucía Moderna. El Marquesado de los Vélez. Editado por Francisco Andújar Castillo y Julián Pablo Díaz López. Almería: Instituto de Estudios Almerienses, 2007: 795-815.

Muñoz López, M. J. «Presentación de Jesús en el templo». En Gratia Plena [Cat. Exp.]. Editado por Juan José Asenjo Peregrina et alii. Córdoba: Cajasur, 2004: 208-210.

Nadal Cañellas, Juan. Jerónimo Nadal: vida e influjo. Bilbao: Mensajero, 2007. Pineda Ramírez De Arellano, Fray Joaquín de. Obras del Venerable Maestro Juan de Ávila, clérigo, apóstol de la Andalucía, tomo noveno. Madrid: Imprenta Real, 1806.

Quintanilla Raso, María de la Concepción. Nobleza y señoríos en el Reino de Córdoba: la Casa de Aguilar (siglos XIV y XV). Córdoba: Monte de Piedad y caja de Ahorros, 1979.

Quintanilla Raso, María de la Concepción. «La biblioteca del marqués de Priego (1518)». En la España Medieval, 1 (1980): 347-383.

Ramírez de Arellano, Teodomiro. Paseos por Córdoba, 1873-1875, 1ª edición facsímil de 1873. Librería Luque 1973², Valladolid 2003.

Ramírez de las Casas-Deza, Luis M. ${ }^{a}$. Indicador cordobés. Manual histórico-topográfico de la ciudad de Córdoba. Córdoba 1856.

Ruiz Jurado, Manuel. «San Juan de Ávila y la Compañía de Jesús». Archivum Historicum Societatis Iesu XL (1971): 153-172.

Ruiz Jurado, Manuel. «Estado actual de los estudios sobre San Juan de Ávila». 


\section{Wenceslao Soto Artuñedo, S.J.}

En El maestro Ávila. Actas del Congreso Internacional. Editado por Conferencia Episcopal Española (Madrid, EDICE, 2002), 637-647.

Ruiz Jurado, Manuel. Jerónimo Nadal. El teólogo de la gracia y la vocación. Madrid: BAC, 2011.

Ruiz Pérez, Pedro. «Casos notables de la ciudad de Córdoba. Espacios de la diferencia en la narrativa barroca». Glosa: Anuario del departamento de filología española y sus didácticas 5 (1994): 169-201.

Sala Balust, Luís. «El H. Sebastián de Escabias, S. I., autor desconocido de los "Casos notables de la ciudad de Córdoba"». Hispania: Revista española de historia 39 (1950): 266-296.

Sala Balust, Luis. Obras completas del Santo Maestro Juan de Ávila. Madrid: BAC, 1952.

Sala Balust, Luis. «La escuela sacerdotal del P. Ávila y la Compañía de Íñigo de Loyola (1546-1556)», en Obras completas del santo maestro Juan de Ávila. Editado por Luis Sala Balust. Madrid: BAC, 1970, 108-185.

Sala Balust, Luis, Obras completas del Santo Maestro Juan de Ávila. Madrid: BAC, 1970.

Saldaña Sicilia, Germán. «Monografía Histórico-Médica de los Hospitales de Córdoba». Boletín de la Academia de ciencias, Bellas Letras y Nobles Artes de Córdoba XIV (1935): 22-32.

Soria Mesa, E. «Los Fernández de Córdoba, un linaje de la nobleza española».

En I Jornadas Cátedra Gran Capitán. Montilla: Ayuntamiento de Montilla, Cátedra Gran Capitán, 2003, 83-98.

Soto Artuñedo, Wenceslao. «Alonso de Barzana, S. I. Apóstol de Andalucía y Sudamérica». Archivo Teológico Granadino 79 (2016): 5-130.

Soto Artuñedo, Wenceslao. «El deseo de las Indias: las cartas indípetas de Alonso de Barzana SJ (1530-1598)». Archivum Historicum Societatis Iesu 85/170 (2016): 405-444.

Soto ARtuÑEDO, Wenceslao. «El apostolado ignaciano de la educación: Institutio puerorum para la reformatio mundi». Manresa. Revista de Espiritualidad Ignaciana 89/353 (2017): 317-328.

Soto Artuñedo, Wenceslao. Alonso de Barzana, SJ, (1530-1597), el Javier de las Indias Occidentales. Bilbao: Mensajero, 2018.

Soto Artuñedo, Wenceslao. «San Juan de Ávila y la Compañía de Jesús. La fundación del colegio de Córdoba», en Vida y obra de San Juan de Ávila. Actas II Congreso Internacional San Juan de Ávila, Córdoba 21 al 23 de noviembre 2019. Editado por Manuel Pérez Moya y Antonio Llamas Vela. Córdoba: Almuzara, 2021: 143-184.

Verdoy, Alfredo. «El jesuita Padre Villanueva (1509-1557)». Manresa 68 (1996): 405-428. 